\title{
Cytotoxicity assessment of stabilized black phosphorus nanosheets tailored by directly conjugated polymeric micelles: theranostic effect against human breast cancer cells
}

\section{Biedulska}

Institute of Biotechnology and Molecular Medicine

\section{P. Jakóbczyk ( $\sim$ pawel.jakobczyk@pg.edu.pl )}

Gdańsk University of Technology

\section{Sosnowska}

Institute of Biotechnology and Molecular Medicine

\section{B. Dec}

Gdańsk University of Technology

\section{A. Muchlińska}

Gdańsk Medical University

\section{A. J. Zaczek}

Gdańsk Medical University

\section{Nidzworski}

Department of Recombinant Vaccine, Intercollegiate Faculty of Biotechnology, University of Gdansk and Medical University of Gdansk

\section{R. Bogdanowicz}

Gdańsk University of Technology

\section{Research Article}

Keywords: Few-layer black phosphorus, bioconjugation, tumor-homing peptides, cytotoxicity, breast cancer

Posted Date: February 24th, 2021

DOl: https://doi.org/10.21203/rs.3.rs-235114/v1

License: (9) This work is licensed under a Creative Commons Attribution 4.0 International License. Read Full License 
Version of Record: A version of this preprint was published at Scientific Reports on April 29th, 2021. See the published version at https://doi.org/10.1038/s41598-021-88791-7. 


\section{Abstract}

The novel procedure of few-layer black phosphorus (FLBP) stabilization and functionalisation was here proposed. The cationic polymer PLL and non-ionic PEG have been involved into encapsulation of FLBP to allow sufficient time for further nanofabrication process and overcome environmental degradation. Two different spacer chemistry was designed to bind polymers to tumor-homing peptides. The efficiency of functionalisation was examined by RP-HPLC, microscopic (TEM and SEM) and spectroscopic (FT-IR and Raman) techniques as well supported by ab-initio modelling. The cell and dose dependent cytotoxicity of FLBP and its bioconjugates was evaluated against HB2, MCF-7 and MDA-MB-231 cell lines.

Functionalisation allowed not only for improvement of environmental stability, but also enhances theranostic effect by abolished the cytotoxicity of FLBP against HB2 cell line. Moreover, modification of FLBP with PLL caused increase of selectivity against highly aggressive breast cancer cell lines. Results indicate the future prospect application of black phosphorus nanosheets as nanocarrier, considering its unique features synergistically with conjugated polymeric micelles.

\section{Introduction}

Since graphene was isolated by Novoselov et al. ${ }^{1}$, two-dimensional (2D) few-layered materials have been attracting increasing attention due to their unique electronic ${ }^{2}$, optical ${ }^{3}$, catalytic ${ }^{4}$, electrochemical ${ }^{5}$, and mechanical ${ }^{6}$ properties in comparison to their multilayered bulk counterparts. The family of 2D materials is a large group of nanomaterials, such as graphene, transition metal dichalcogenides (molybdenum disulfide), MXene ${ }^{7}$, and phosphorene, which was discovered in 2014. Phosphorene shows properties such as anisotropy, high carrier mobility, mechanical flexibility, and a tunable bandgap from $0.3 \mathrm{eV}$ (bulk) to $2.0 \mathrm{eV}$ (single layer) ${ }^{8}$. For biomedical applications, its strong absorption in the ultraviolet (UV) and near-infrared (NIR) regions ${ }^{9,10}$, biocompatibility, and great biodegradability in the physiological environment are especially important. These properties of phosphorene have attracted special attention

for clinical applications in biomedicine such as phototherapy ${ }^{11,12}$, drug delivery ${ }^{13}$, biosensing ${ }^{14,15}$, and theranostics ${ }^{10,16}$.

Although studies of biomedical applications of FLBP have made a lot of progress, there are still some problems that need to be solved before its clinical transition. Various factor such as size, concentration and test cell line have a great impact on toxicity and treatment effects, it is very important to find an effective method to fabricate FLBP with uniform size and high production. Another remarkable but still underexplored feature of phosphorene is it potential as a carrier for biological and biomedical molecules. Surface functionalisation or conjugation is commonly used to increase stability, improve drug loading and cellular uptake, actively target cancer cells and tumors. To environmental stability of phosphorene is also concern and specialized coatings are necessary to ensure stable performance of the sensor. In this regard, the number functionalisation with other nanoparticulate system or polymers (poly(ethylene glycol) (PEG), Poly-L-lysine (PLL), Poly(lactic-co-glycolic acid) (PLGA), polysialic acid or glycolic acid) have been developed ${ }^{17,18}$. The fabrication of BP nanoplatform with polymers could be efficient route to achieve 
stability of nanomaterial and enhancement of its properties. On the one hand, the involvement of nonionic, flexible, hydrophilic and biocompatible PEG polymer allowed to resolve the problem with nonspecific absorption on the nanomaterial surface ${ }^{19-23}$. While, application of ionic PLL polymer in functionalisation of nanosheet surface may be a new strategy to overcome drug resistance related to deficient transport ${ }^{24,25}$. The polycationic nature of poly-L-lysine enhanced the interaction with plasmid DNA and ensured the protection of biomolecules from nuclease degradation ${ }^{26,27}$. These functionalised strategy allow to applied BP in different application area, considering unique features of nanosheets itself or utilizing advantage of synergistic effect of applied components. Constructing such a nanoplatform not only enables encapsulation of specific recognition ligands, but can result in targeted drug delivery to the tumor cell ${ }^{28-30}$.

Peptides may offer new therapeutic opportunities due to low immunogenicity, excellent tissue penetration and low production cost ${ }^{31,32}$. Specific targeting of therapeutic moieties to cancer tissue may be a valuable option, especially when local treatment is not possible. The positively charged amino acid residues have great potential as an active targeting ligand ${ }^{33-35}$. Peptides rich in KRK motif could promote membrane fusion through electrostatic interaction with lipid and enable the interaction with negatively charged $D N A^{36}$. This short sequence was uses because it possesses ability to accumulation both on the surface of tumor vessels and within tumor tissue after intravenous injection ${ }^{37,38}$.

Next, peptides which can be selectively delivered to tumors are very attractive biomolecules for the prevention and treatment of cancer. The arginine-glycine-aspartic acid (RGD) sequence plays a crucial role in cellular adhesion of extracellular fibronectins ${ }^{39}$. RGD motif exhibit a strong affinity and selectivity to alpha v beta 3 integrin on the cell surface and enter the cytoplasm receptor-mediated endocytosis ${ }^{40}$. Within the present work, RGD sequence was used due to the fact that RGD triad is a typical cell-binding domain in order to effective targeting of endothelial cells in tumor vasculature and suppressing angiogenesis and tumor growth. Many research effort have been paid to the determination of therapeutic efficiency and selective tumor targeting ability of black phosphorus. Unfortunately, studies describe the difference in efficiency of the applied linker in delivery systems are still missing. Drug delivery studies with different structural linkers are often performed in different tumor models with a wide dose range, which makes them difficult to compare. Therefore extensive investigations about BP and its bioconjugates various applications as well as critical evaluation on their toxicity assessment are very crucial before introducing it into practical area.

The novel strategies of FLBP nanosheets functionalisation are presented in the paper allowing for enhancement of its environmental stability against air or aqueous solvents. We applied two different strategies of bioligands grafting studying influence of ionic character, surface conformation and biological activity of poly-L-lysine (PLL) and poly-ethylene glycol (PEG), in order to overcome FLBP nanosheets degradation. To the best of our knowledge, the functionalisation of nanosheet incorporating bioligands - tumor-homing peptides with KRK and RGD motifs as a potential drugs in breast cancer therapy were not reported in the literature up to date. The toxicity investigation of FLBP itself and its 
modifications were carried out in two model of breast cancer lines MCF-7 (luminal A subtype of breast cancer) and MDA-MB-231 (highly aggressive, triple-negative breast cancer).

\section{Materials And Methods \\ 2.1. Materials}

The black phosphorus was purchased from Smart Elements. N,N-Dimethylformamide (DMF) was collected from Sigma Aldrich. All reagents were analytical grade and were used without further purification. The purge gas (argon) used for the liquid exfoliation process was purchased from Air Liquid and had the highest purity class. The Fmoc-protected amino acids for the synthesis of the peptides were purchased from Iris Biotech GmbH (Marktredwitz, Germany). The TentaGel S PHB resin was acquired from Rapp Polymere GmbH (Tuebingen, Germany). The N,N-Diisopropylethylamine (DIPEA), 2-(1Hbenzotriazole-1-yl)-1,1,3,3-tetramethylaminium tetrafluoroborate (TBTU), triisopropylsilane (TIS), Nhydroxysuccinimide (NHS), (1-ethyl-3-(3-dimethylaminopropyl)carbodiimide hydrochloride (EDC) and poly-L-lysine hydrobromide (30,000-70,000) 1-methylimidazol (Melm) and 2,4,6-mesitylene-sulfonyl-3nitro-1,2,4-triazol (MSNT Novabiochem ${ }^{\circledR}$ ) were received from Sigma Aldrich Company. The Hydroxypoly(ethylene glycol) amine $\mathrm{NH}_{2}-\mathrm{PEG}-\mathrm{OH} \cdot \mathrm{HCl}(\mathrm{MW} 2000)$ was obtained from JenKem Technology USA. The peptide synthesis-grade $\mathrm{N}, \mathrm{N}$-dimethylformamide was purchased from Acros Organics. The Acetonitrile HPLC gradient grade and trifluoroacetic acid for the HPLC were purchased from Alfa Aesar. Doubly distilled water (Hydrolab-Reference purified) with conductivity not exceeding $0.05 \mu \mathrm{cm}^{-1}$ was used. All other chemicals used in this study were analytical reagent grade and used without further purification.

\subsection{Parameters of FLBP properties ab-initio study}

The few-layer black phosphorus model was prepared in the Quantum ATK software from Synopsys ${ }^{41}$ in order to understand how surface oxidation influences adsorption of linker molecules. The created supercell was constructed using the ( $\mathrm{C} \mathrm{m} \mathrm{c}$ a) space group. The Center Orthorhombic Bravais lattice was used in all slabs. The properties were calculated with Generalized Gradient Approximation using PerdewBurke-Ernzerh of ${ }^{42}$ (GGA-PBE). The description of the Van der Waals forces was performed with the Grimme-D2 corrections method. The Fritz-Haber Institute (FHI) pseudopotential code with Double Zeta Polarized basis set was used. The reference point for the simulation parameters was bulk phosphorus and was calculated with a bandgap of $0.284 \mathrm{eV}$, which is in great accordance to the experimental value $0.3 \mathrm{eV}^{43,44}$. Surface configurations were modelled with the exact same parameters as bulk phosphorene including a $30 \AA \AA$ vacuum in the Y-direction in order to create the surface model.

\subsection{Liquid exfoliation of black phosphorus}

Few-layer black phosphorus (FLBP) was prepared from pre-ground black phosphorus (BP) crystals (60$70 \mathrm{mg}$ ) dispersed in deoxygenated anhydrous dimethylformamide $(7 \mathrm{~mL})$. During the liquid exfoliation process, the sample was kept in an ice bath, at a temperature from 0 to $3^{\circ} \mathrm{C}$, under a stream of argon 
using a horn probe ultrasonicator (Bandelin Sonopuls HD2200, $20 \mathrm{kHz}$ ). The sonication power and time amplitudes were $40 \mathrm{~W}$ and $0.5 \mathrm{~s} / 0.5 \mathrm{~s}$, respectively. The FLBP suspension in DMF was processed for 120 min. and afterwards was centrifuged at $6000 \mathrm{rpm}$ for 5 minutes to remove the residual unexfoliated particles, yielding supernatant. Next, the exfoliation was repeated for the unexfoliated BP for another $2 \mathrm{~h}$. After this step, the centrifugation of the re-exfoliated suspension was repeated. Finally, the FLBP with a concentration of 1.2-1.5 mg per solvent millilitre was used for the reaction as shown in Fig. 1.

\subsection{Synthesis and purification of tumor-homing peptides}

The H-SPRGDGG-OH (RGD) and H-SPKRKGG-OH (KRK) peptides were synthesised by standard solid phase 9-fluorenylmethoxycarbonyl (Fmoc) chemistry ${ }^{26,27}$ using a Magnum Nova 10 microwave reactor (Ertec, Poland). Tentagel S PHB resin with $0.27 \mathrm{mmol} \mathrm{g}^{-1}$ capacity was applied to produce C- terminal $\mathrm{COOH}$ peptides. Anchoring the first Fmoc-amino acids to the hydroxyl solid support was performed by esterification of the carboxylic acid with 2,4,6-mesitylene-sulfonyl-3-nitro-1,2,4-triazol (MSNT) in the presence of 1-methylimidazol (Melm) ${ }^{27}$. The remaining coupling steps were carried out at threefold excess over the resin capacity. Before each coupling cycle, the pre-activation step of Fmoc-AA was performed by the addition of 2.85 equivalents of $N, N$-Diisopropylethylamine (DIPEA) and 6.00 equivalents of 2-(1 H-benzotriazole-1-yl)-1,1,3,3-tetramethylaminium tetrafluoroborate (TBTU) to the amino acid solution in DMF, respectively. Microwave-assisted coupling reactions were repeated twice under constant conditions ( $7 \mathrm{~W}$ of power, $60^{\circ} \mathrm{C}, 5 \mathrm{~min}$ ). The Fmoc group deprotection involved $20 \%$ piperidine solution in DMF and was carried out under $5 \mathrm{~W}$ of microwave irradiation power twice for 4 minutes at $60^{\circ} \mathrm{C}$. During microwave-assisted SPPS, continuous stirring was maintained by using a nitrogen stream. Cleavage of the desired peptide from the resin with simultaneous side chain protecting group removal were performed by treatment with a mixture containing $95.00 \%$ trifluoroacetic acid (TFA), $2.50 \%$ triisopropylsilane (TIS) and $2.50 \%$ water for 2 hours at room temperature. After cleavage from the resin, the peptides were precipitated in cold, anhydrous ethyl ether and separated from soluble non-peptide substances by centrifugation $\left(4^{\circ} \mathrm{C}, 4000 \mathrm{rpm}, 3 \times 15 \mathrm{~min}\right.$.). The obtained pellets were dissolved in deionised water and the obtained solutions were lyophilised. The mass analysis of crude peptides was performed by MatrixAssisted Laser Desorption/lonisation Time of Flight Mass Spectrometry MALDI-TOF MS (Bruker, Germany) with a-Cyano-4-hydroxycinnamic acid (CCA) and 2,5-Dihydroxybenzoic acid (DHB) as a matrix. The crude products were purified by a HPLC system (Shimadzu Prominence Modular HPLC SPD-20A UV$V i s$ detector) using a semi-preparative reverse phase Phenomenex Gemini C18 column $(250 \mathrm{~mm} \times 30$ $\mathrm{mm}, 110 \AA, 5 \mu \mathrm{m})$. A linear gradient elution was applied from 5 to $20 \%$ of solvent $B$ at a flow rate of 18 $\mathrm{mL} \mathrm{min}^{-1}$ for 60 minutes. The gradient used water (A) and acetonitrile (B) as eluants containing $0.10 \%$ TFA. The UV detection was carried out at $\lambda_{1}=224 \mathrm{~nm}$ and $\lambda_{2}=254 \mathrm{~nm}$. The purity of the desired peptides was evaluated using an analytical reverse-phase HPLC Shimadzu system (Shimadzu Prominence-i LC2030C) with a Cosmosil C18 column $(4.60 \mathrm{~mm} \times 250 \mathrm{~mm}, 90 \AA, 5 \mu \mathrm{m})$ using the linear gradient method from 0 to $100 \%$ solvent $B$ for $30 \mathrm{~min}$ at a flow rate of $1.50 \mathrm{~mL} \mathrm{~min}-1$ with UV detection at $\lambda 1=224 \mathrm{~nm}$ and $\lambda 2=254 \mathrm{~nm}$. Fractions containing above 98\% (by analytical HPLC) of the expected peptide were pooled 
and lyophilised. MALDI TOF mass analysis of the purified peptides confirmed the formation of the desired products.

\subsection{Functionalisation procedure of FLBP \\ 2.5.1. Preparation of FLBP-Poly-L-lysine-peptides}

Preparation of the FLBP-PLL-peptide structure was performed in two stages. In the first part peptide attach to the linker via EDC/NHS mediation, which provides a covalent amide bond between the carboxyl group of the linker (PLL) and an N-terminal amine moiety of the peptide without the addition of a spacer. Briefly, $38.10 \mathrm{mg}$ of $\mathrm{N}$-hydroxysuccinimide (NHS), $63.70 \mathrm{mg}$ of 1-Ethyl-3-(3-dimethylaminopropyl) carbodiimide hydrochloride EDC, and $1.60 \mathrm{mg}$ of $\mathrm{PLL} \bullet \mathrm{HBr}$ were dissolved in $1.50 \mathrm{~mL}$ of ultrapure water. For linkage, $2 \mathrm{~mL}$ of $12 \mathrm{mM}$ aqueous solution of RGD peptide was added to the reaction mixture. Poly-Llysine modification was carried out under stirring continuous for 24 hours at room temperature. The progress of the reaction was monitored by Reverse Phase High Performance Liquid Chromatography (RPHPLC). Afterwards, the modified linker was centrifuged $\left(9,000 \mathrm{rpm}, 4^{\circ} \mathrm{C}\right)$ to remove unconjugated peptide. After centrifugation, the obtained linkage product was lyophilised.

In the next step, the conjugation of PLL-peptide with FLBP was carried out. The FLBP was resuspended in $2 \mathrm{~mL}$ of ultrapure water and then $2 \mathrm{~mL}$ the desired PLL-RGD aqueous solution was added. The reaction mixture was placed in a round-bottom flask in an ice bath $\left(0^{\circ} \mathrm{C}\right)$ and continuous stirring was maintained for 1 hour through an argon stream. After this period, the sample was incubated for $24 \mathrm{~h}$ at $4^{\circ} \mathrm{C}$.

Afterwards, the obtained reaction mixture was centrifuged at $9000 \mathrm{rpm}$ for 30 minutes. The obtained black powder was lyophilised. The same synthetic protocol was applied for the conjugation of FLBP with PLL-KRK.

In order to verify the surface modification of the nanoparticles with the linker-peptides, the prepared samples were lyophilised via an Alpha 2-4 LSCbasic Freeze Dryer Martin Christ (0.070 Mbar Vacuum, T = $-80^{\circ} \mathrm{C}$ ), and then subjected to Scanning Electron Microscopy, Transmission Electron Microscopy analysis and spectroscopic assay including Raman and FT-IR spectra to confirm successful conjugation of the nanoparticles with the peptides.

\subsubsection{Preparation of FLBP-PEG-peptides}

The conjunction between the few-layer black phosphorus and the PEG-peptide couple can only take place after prior activation of the hydroxyl groups in the PEG and then pegylation of a peptide. In order to covalently attach the peptide molecule to hydroxy-terminated PEG $\left(\mathrm{H}_{2} \mathrm{~N}-\mathrm{PEG}-\mathrm{OH}\right)$, the chloroformate activation strategy of hydroxyl groups on end-functionalised PEG was used. The reaction between the peptide and the $\mathrm{H}_{2} \mathrm{~N}$-PEG-OH takes place between the activated $\mathrm{H}_{2} \mathrm{~N}$-PEG-p-nitrophenyl carbonate molecule which is reactive towards the a-amino group of the peptide. For this purpose, the linear $\mathrm{H}_{2} \mathrm{~N}$ PEG-OH (Mw = $\left.2000 \mathrm{~g} \mathrm{~mol}^{-1}\right) 0.20 \mathrm{~g}, 0.10 \mathrm{mmol}$ was dissolved in $5 \mathrm{~mL}$ of dry toluene. To this solution, 4nitrophenyl chloroformate $(60.45 \mathrm{mg}, 0.30 \mathrm{mmol})$ and ethylene chloride $(2 \mathrm{~mL})$ were added and the $\mathrm{pH}$ 
was brought to 8.00 with TEA $(120 \mu \mathrm{L}, 0.86 \mu \mathrm{mol})$. The obtained $\mathrm{H}_{2} \mathrm{~N}$-PEG-p-nitrophenyl carbonate was precipitated with diethyl ether $(20 \mathrm{~mL})$ and the resulting product was purified by crystallisation from ethyl acetate.

Afterwards, the H-SPRGDGG-OH (RGD) peptide $(15.90 \mathrm{mg}, 24.60 \mu \mathrm{mol})$ was dissolved in $2.50 \mathrm{~mL}$ of $\mathrm{H}_{2} \mathrm{O} / \mathrm{CH}_{3} \mathrm{CN}(90: 1)$ in the presence of TEA $(3.4 \mu \mathrm{L}, 24.20 \mu \mathrm{mol})$ and previously obtained $\mathrm{H}_{2} \mathrm{~N}$-PEG- $p$ nitrophenyl carbonate $(10.50 \mathrm{mg}, 4.88 \mu \mathrm{mol})$ was added. The aqueous solution was kept at room temperature and stirred for 48 hours. The $\mathrm{pH}$ of the solution was brought to a $\mathrm{pH} 3.00$ and the product was extracted into chloroform (five times, $50 \mathrm{~mL}$ each), concentrated and precipitated with diethyl ether.

The H-SPKRKGG-OH (KRK) peptide $(20.10 \mathrm{mg}, 27.58 \mu \mathrm{mol})$ was dissolved in $2.50 \mathrm{~mL}$ of $\mathrm{H}_{2} \mathrm{O} / \mathrm{CH}_{3} \mathrm{CN}$ (90:1) in the presence of TEA $(3.80 \mu \mathrm{L}, 27.30 \mu \mathrm{mol})$ and previously obtained $\mathrm{H}_{2} \mathrm{~N}$-PEG-p-nitrophenyl carbonate $(10.50 \mathrm{mg}, 4.88 \mu \mathrm{mol})$ was added. The aqueous solution was kept at room temperature and stirred for 48 hours. The $\mathrm{pH}$ of the solution was brought to 3.00 and the product was extracted into chloroform (five times, $50 \mathrm{~mL}$ each), concentrated and precipitated with diethyl ether. The resultant conjugates were characterised by HPLC chromatography using a Cosmosil C18 (4.60 x $250 \mathrm{~mm}$, particle size $5 \mu \mathrm{m}$ ) reverse phase column. The gradient used water $(A)$ and acetonitrile (B) as eluants containing both $0.10 \%$ TFA was from 0 to $100 \% \mathrm{~B}$ for $30 \mathrm{~min}$, the flow rate was $1.50 \mathrm{~mL} \mathrm{~min}{ }^{-1}$ with UV detection at $\lambda_{1}=214 \mathrm{~nm}$ and. $\lambda_{2}=254 \mathrm{~nm}$. The masses of the obtained PEG-peptide conjugates were confirmed by MS analysis. MALDI-TOF mass spectrometry was carried out on a SCIEX TOF/TOF ${ }^{\text {TM }} 5800$ System works using the MALDI ionisation technique (Matrix Assisted Laser Desorption lonisation). The matrix used in the MALDI-TOF mass spectrometry was 2,5-dihydroxybenzoic acid (DHB).

FLBP was modified with $\mathrm{H}_{2} \mathrm{~N}-\mathrm{PEG}-\mathrm{RGD}-\mathrm{OH}$ and $\mathrm{H}_{2} \mathrm{~N}-\mathrm{PEG}-\mathrm{KRK}-\mathrm{OH}$ conjugates, respectively. FLBP gathered by liquid exfoliation $\left(0.26 \mathrm{mg}\right.$ ) was re-suspended in $4 \mathrm{~mL}$ of aqueous solution $\mathrm{H}_{2} \mathrm{~N}$-PEG-RGD-OH conjugate $\left(2.50 \mathrm{mg} \mathrm{mL}^{-1}\right)$. After stirring for 24 hours, the obtained $\mathrm{H}_{2} \mathrm{~N}$-PEG-RGD-OH-loaded FLBP nanoparticles (FLBP-PEG-RGD) were centrifuged and washed with deoxygenated water. The same protocol was applied for modification of FLBP with $\mathrm{H}_{2} \mathrm{~N}-\mathrm{PEG}-\mathrm{KRK}-\mathrm{OH}$ peptide and obtained $\mathrm{H}_{2} \mathrm{~N}-\mathrm{PEG}$ KRK-OH-loaded FLBP nanoparticles (FLBP-PEG-KRK).

In order to verify the modification of the FLBP surface with the PEG-peptide conjugates, the prepared samples were lyophilised and then subjected to Transmission Electron Microscopy, Scanning Electron Microscopy analysis and spectroscopic assay including Raman and FT-IR spectra.

\subsection{In vitro cytotoxicity}

The in vitro cytotoxicity of the PEG, KRK, RGD, PLL and FLBP, FLBP-PEG-RGD, FLBP-PEG-KRK, FLBP-PLLRGD and FLBP-PLL-KRK was assessed in MCF-7, MDA-MB-231 (human breast adenocarcinoma cell lines) and HB2 (human mammary luminal epithelial cell line) cells by a standard methyl thiazolyl tetrazolium (MTT) assay. MCF-7 and MDA-MB-231 were cultured in DMEM supplemented with $10 \%$ foetal bovine serum (FBS) and 1\% penicillin-streptomycin solution. HB2 was cultured in DMEM supplemented 
with $10 \%$ foetal bovine serum (FBS), $1 \%$ penicillin-streptomycin solution, $5 \mu \mathrm{g} \mathrm{mL}^{-1}$ hydrocortisone, and 5 $\mu \mathrm{g} \mathrm{mL}^{-1}$ insulin. The cells were routinely tested for mycoplasma contamination. All of the media and their supplements were from Sigma-Aldrich (Saint Louis, MO, USA) or HyClone (GE Healthcare, Chicago, IL, USA). $7 \times 10^{3}$ viable cells per well were seeded in 96-well plates, and allowed to adhere overnight at $37^{\circ} \mathrm{C}$. After 24 hours of incubation, culture medium was replaced with fresh medium and the cells were treated with different concentrations of PEG, KRK, RGD, PLL, FLBP, FLBP-PEG-RGD, FLBP-PEG-KRK, FLBP-PLLRGD, or FLBP-PLL-KRK $\left(0,0.80,4,20 \mu \mathrm{g} \mathrm{mL}^{-1}\right)$ for $72 \mathrm{~h}$. Subsequently $20 \mu \mathrm{l}$ of MTT working solution (5 $\mathrm{mg} \mathrm{mL}^{-1}$ ) was added to each well and the plate was incubated for 1 hour at $37^{\circ} \mathrm{C}$. The medium was then aspirated, and the formed formazan crystals were solubilised by adding $100 \mu$ l of DMSO (dimethyl sulfoxide). The absorbance was measured at $570 \mathrm{~nm}$ using a microplate reader (Synergy ${ }^{\mathrm{TM}} \mathrm{H} 1$, BioTek, USA). The cell viability was calculated using the following formula: cell viability = Asample $/$ Acontrol $x$ $100 \%$, where $A$ is the absorbance at $570 \mathrm{~nm}$. Data are presented as means $\pm S D$ from at least three independent experiments. Comparative data were analysed with the unpaired Student's t-test using the IBM SPSS statistics software.

\subsection{Characterisation techniques}

The Raman spectra were collected on a micro-Raman spectrometer (InVia, Renishaw, United Kingdom) with a 532 excitation laser (Ar ion laser), and the wavenumber was in the range of $300-600 \mathrm{~cm}^{-1}$. For the identification of functional groups in the obtained synthesis products, the FT-IR spectra were produced with a Bruker IFS66 spectrometer. The compounds were prepared for spectral analysis by using potassium bromide (KBr) pellets. The scanning electron microscope (SEM) (FEI Quanta FEG 250) allows the the evolution of the surface morphology to be observed. A $10 \mathrm{kV}$ beam accelerating voltage was used with a Secondary Electron-Everhart-Thornley Detector (SE-ETD) working in a high vacuum mode pressure of $10^{-4} \mathrm{~Pa}$ to record high-resolution, high-magnification images of backscattered electrons emitted from the samples' surfaces.

The morphology of the exfoliated and functionalised FLBPs were examined by a Tecnai G2 Spirit BioTWIN (FEI) transmission electron microscope (TEM) operated at an accelerating voltage of $120 \mathrm{kV}$ to observe changes of the surface as a consequence of nanoparticle conjugation with the peptides. Briefly, $10 \mu \mathrm{L}$ of each sample was drop cast onto a 300 mesh Copper TEM grid coated with Formvar Carbon film (EM Resolution). After deposition, the excess of solvent was filtered. Grids were rapidly transferred to the microscope with a minimal amount of light exposure to minimise the photo-oxidative degradation.

\section{Results And Discussion}

\subsection{Tumor-homing peptide characterisation}

The crude peptides were purified by semi-preparative RP-HPLC on a C18 Column. The degree of purity for a single eluted peak of H-SPRGDGG-OH and H-SPKRKGG-OH peptides was always above $98 \%$ according to the analytical HPLC with a retention time at $4.757 \mathrm{~min}$. and $4.595 \mathrm{~min}$., respectively. The molecular 
weight of pure peptides was determined using MALDI TOF mass spectrometry. The observed pseudomolecular ion $\left[\mathrm{M}+\mathrm{H}^{+}\right.$at $645.70 \mathrm{Da}$ in the mass spectrum of the RGD and 729.20 Da in the case of the KRK were consistent with the calculated molecular weights of $644.60 \mathrm{Da}$ and 728.80 Da, respectively. The designed and synthesised peptides possessed a free carboxyl group on the $C$-terminus in order to further conjugate with the poly-L-lysine and OH-PEG-NH $\mathrm{N}_{2}$ linkers.

\subsection{Characterisation of black phosphorus after attachment of linker-peptide fragments}

In the presented studies, two-step bioconjugation of the linker-peptide hybrid to the black phosphorus nanoparticles was used. The first step involved covalent bioconjugation of the peptide with the poly-Llysine (PLL) or poly(ethylene glycol) (PEG) linker. However, in the second step, the non-covalent immobilisation of the obtained hybrid (PLL-peptide or PEG-peptide) to the FLBP surface was applied. The RGD and KRK peptides were utilised as functional ligands to be conjugated to the surface of few-layer black phosphorus nanoparticles.

\subsubsection{FLBP functionalisation with poly-L-lysine-peptide conjugate}

The PLL linker was used to coat and protect the surface of the FLBP nanoparticles from degradation and to decrease non-specific interactions. The synthesised peptides were functionalised to the linker through $\mathrm{N}$-terminal covalent conjugation using the carbodiimide coupling reaction aiming at precise dual targetting efficiency. The carboxylic group of the PLL could be reacted with the primary amine group of the obtained peptides by a condensation reaction to yield amide bonds. It should be noted that the carboxyl moiety must be chemically modified to achieve this goal. For this reason, EDC/NHS chemistry was applied to form a covalent amide bond without any addition of a spacer ${ }^{27}$. Briefly, the carboxylic group of the poly-L-lysine reacted with (1-ethyl-3-(3-dimethylaminopropyl)carbodiimide hydrochloride (EDC) to form an O-acylisourea intermediate which is unstable in an aqueous solution. Therefore, in a covalent immobilisation protocol, $\mathrm{N}$-hydroxysuccinimide (NHS) was involved to increase the efficiency or formation of a dry-stable, amine reactive by-product. After formation of a reactive NHS ester from the carboxylic group, which is considerably more stable than the 0 -acylisourea intermediate, the activated group could be efficiently coupled to primary amines at a physiologic $\mathrm{pH}^{27}$. The $\mathrm{N}$-terminal primary amine group of the peptide covalently binds to the reactive ester to form a peptide bond without the addition of a spacer (Fig. 2). As a consequence, covalent bioconjugation provides stronger bond formation and a more stable hybrid than physisorption.

The progress of covalent immobilization of poly-L-lysine with the RGD peptide was monitored by the Reversed Phase High Performance Liquid Chromatographic method with UV detection. The RP-HPLC chromatograms of the substrates showed one sharp peak each with the following retention times: RGD: 4.757 min.; KRK: 4.595 min. and PLL: 7.295 min, respectively (Fig. 3). 
The RP-HPLC reaction monitoring started immediately after adding the linker with coupling agents to the selected peptide solution. The presented approach focussed on a fast analysis run to observe any changes during the conjugation reaction progress. As can be seen in Fig. 3, after the addition of the PLL with the crosslinker bioconjugate reagents (EDC and NHS) to the peptide solution, the signals corresponding to the substrate disappeared. At the same time, two new peaks appeared in the reaction mixtures' HPLC chromatograms with retention times in the range 3.013-3.096 and 4.043-4.125 minutes, respectively. After $24 \mathrm{~h}$, the HPLC chromatogram was recorded to evaluated the progress of bioconjugation. One major, sharp peak with a retention time of 3.013 min was observed, which corresponded to the formation of the expected PLL-RGD hybrid product. The shape of the reaction mixture's HPLC chromatogram remained essentially constant thereafter for $48 \mathrm{~h}$. Therefore, the reaction was considered to be completed. The efficiency of the poly-L-lysine coupling reaction with the PLL-KRK$\mathrm{OH}$ peptide was evaluated in the same manner.

The qualitative RP-HPLC analysis presented in Fig. 3 revealed that the expected product was obtained after $24 \mathrm{~h}$. The chromatogram is characterised by the presence of one sharp peak associated with the formation of the PLL-KRK conjugate with a retention time of $3.096 \mathrm{~min}$. As in the case of the PLL-RGD hybrid, no addition signals appeared after 48 hours of reaction.

A simple, noncovalent modification strategy was applied to obtained poly-L-lysine - peptide conjugates with few-layer black phosphorus (FLBP-PLL-peptide). The bioconjugation involved the combination of hydrophobic and electrostatic interactions of the PLL-peptide fragments and the FLBP surface. Briefly, poly-L-lysine belongs to a cationic polymer group with an isoelectric point around $9.50{ }^{45}$. The acid-base equilibria studies revealed that three pKa constant values could be determined. In a strong acidic environment, the first $\mathrm{pKa}_{1}$ value equals 2.15 could be attributed to deprotonation of the carboxyl group ${ }^{46}$. After the $\mathrm{pH}$ value exceeded 9.00 , the second proteolytic equilibria was established. The $\mathrm{pKa}_{2}$ value equalling 9.16 corresponded to deprotonation of the epsilon amine moiety on the polymer side chain. Moreover, in strong alkaline conditions ( $\mathrm{pH}>10.50)$, the third deprotonation step of poly-L-lysine with a $\mathrm{pKa}_{3}$ value equalling 10.67 was observed as a results of the loss of a proton of the alpha amine group. Due to the above, the PLL linker should be positively charged under physiological conditions as a consequence of the protonated amine group in the polymer side chains. As a results, strong electrostatic interactions are formed between the cationic PLL linker and the negative charge on the deprotonated $\mathrm{P}_{\mathrm{x}} \mathrm{O}_{\mathrm{y}}$ group on few layer black phosphorus. Moreover, the adheration of the PLL-peptides hybrid to the FLBP surface could be stabilised by hydrophobic force. During this process, the non-polar butyl chains of the poly-L-lysine are exposed for interaction with the few-layer black phosphorus nanomaterial. The noncovalent binding modes, including the synergetic effect of hydrophobic and electrostatic forces, contributed to the FLBP-PLL-peptides' strong assembly. The efficiency of the conjugation and nanoparticles' functionalisation were confirmed by transmission electron microscopy (TEM), scanning electron microscopy (SEM) and spectroscopic techniques (Raman and FT-IR). 
The application of the covalent immobilisation protocol to coupling the PLL linker with the peptide allowed a stronger bond and therefore a more stable hybrid to form than physisorption. The biocompatible FLBP-PLL-peptide conjugates were synthesised according to the proposed non-covalent strategy. The attachment of the cationic linker with the peptide to the surface of the black phosphorus was stabilised by electrostatic and hydrophobic interaction. The proposed non-covalent functionalisation of the FLBP surface by poly-L-lysine improved the nanomaterial stability. The partial surface oxidation of the FLBP could even improve the properties of the FLBP-PLL. Application of RP-HPLC analysis for preliminary screening of covalent conjugation of the linker and peptide proved to be an efficient and practical method to be used in further investigations.

\subsubsection{FLBP functionalisation with PEG-peptide conjugate}

The FLBP surface was modified with a positively charged anchor formed the polyethylene glycol-aminepeptide connection $\left(\mathrm{H}_{2} \mathrm{~N}-\mathrm{PEG}\right.$-peptide) via electrostatic adsorption, and presents the dangling PEGpeptide chains to the aqueous environment. It is well established that surface coating effectively enhances their biocompatibility and physiological stability. In order to obtain PEG-peptide covalent conjugation, we applied a methodology for site-specific peptide PEGylation. In the first step, hydroxyterminated PEG $\left(\mathrm{H}_{2} \mathrm{~N}-\mathrm{PEG}-\mathrm{OH}\right)$ was activated to PEG- $p$-nitrophenyl carbonate using a chloroformate activation reaction. Afterwards, the peptides were PEGylated by reacting the $N$-terminal serine residue with PEG-p-nitrophenyl carbonate, to produce a stable carbamate linkage between the PEG and peptide (Fig. 4).

The PEG-peptide conjugates were characterised by HPLC as well as MALDI-TOF mass spectrometry. The progress of the formation of the PEG-peptide conjugates was monitored by HPLC analysis of the reaction mixture at different time intervals $(0,24$ and 48 hours). The HPLC chromatograms of the individual substrates showed a main peak with the respective retention times of RGD, 4.757 min.; KRK, 4.595 min.; $\mathrm{H}_{2} \mathrm{~N}-\mathrm{PEG}-\mathrm{OH}, 8.876$ min.; and $\mathrm{H}_{2} \mathrm{~N}-\mathrm{PEG}-p$-nitrophenyl carbonate, $18.085 \mathrm{~min}$. (Fig. 5). The degree of completion of attachment of the PEG with the RGD and KRK peptide, respectively, indicated in both cases that the reaction was complete within $24 \mathrm{~h}$. After this time, there were no significant changes in the course of the reaction, The chromatograms of the obtained bioconjugates of $\mathrm{H}_{2} \mathrm{~N}-\mathrm{PEG}-\mathrm{RGD}-\mathrm{OH}$ and $\mathrm{H}_{2} \mathrm{~N}$ PEG-KRK-OH demonstrate the main product at retention times of 4.707 and 4.579 min, respectively (Fig. 5).

The MALDI-TOF mass spectra of the native $\mathrm{H}_{2} \mathrm{~N}-\mathrm{PEG}-\mathrm{OH}$, activated $\mathrm{H}_{2} \mathrm{~N}-\mathrm{PEG}$ - $p$-nitrophenyl carbonate, as well as the $\mathrm{H}_{2} \mathrm{~N}-\mathrm{PEG}-\mathrm{RGD}-\mathrm{OH}$ and $\mathrm{H}_{2} \mathrm{~N}-\mathrm{PEG}-\mathrm{KRK}-\mathrm{OH}$ conjugates are shown in Fig. 6 . The PEG mass spectra are characterised by a series of peaks where the mass difference between each adjacent peak is 44 mass units, which corresponds to the mass of a single ethylene glycol repeat unit and confirms that the analyte is the PEG polymer. The spectrum of the $\mathrm{H}_{2} \mathrm{~N}-\mathrm{PEG}-\mathrm{OH} 2000$ contains oligomer peaks extending from approximately $\mathrm{m} / \mathrm{z} 1735$ to 2660 . The number-average the molecular weight of the $\mathrm{H}_{2} \mathrm{~N}$ PEG-OH 2000 is $1955.1 \mathrm{Da}$. Analysis of the peak at $\mathrm{m} / \mathrm{z}=1955,1$ reveals that this peak is a PEG with 44 repeat ethylene glycol units. The average MW measured for the $\mathrm{H}_{2} \mathrm{~N}$-PEG-p-nitrophenyl carbonate (2150 
$\mathrm{Da}$ ) is in good agreement with the theoretical value (2134 Da). The spectrum of the $\mathrm{H}_{2} \mathrm{~N}-\mathrm{PEG}-p$ nitrophenyl carbonate compared to the native $\mathrm{H}_{2} \mathrm{~N}-\mathrm{PEG}-\mathrm{OH}$ spectrum resulted in the whole mass distribution curves being shifted to higher molecular weights while the shape of the curves show no significant changes, indicating a complete coupling reaction.

After the attachment of the RGD peptide, the number average molecular weight of the $\mathrm{H}_{2} \mathrm{~N}-\mathrm{PEG}-\mathrm{RGD}-\mathrm{OH}$ connection is expected to be $2612.6 \mathrm{Da}$. The experimental mass $(2603.9 \mathrm{Da})$ is well within the expected range. The calculated mass of the $\mathrm{H}_{2} \mathrm{~N}-\mathrm{PEG}-\mathrm{KRK}-\mathrm{OH}$ conjugate $(2696.8 \mathrm{Da})$ is in accordance with the observed mass (2690.7 Da). For both the $\mathrm{H}_{2} \mathrm{~N}-\mathrm{PEG}-\mathrm{RGD}-\mathrm{OH}$ and $\mathrm{H}_{2} \mathrm{~N}-\mathrm{PEG}-\mathrm{KRK}-\mathrm{OH}$ conjugates, the experimental MALDI-TOF MS results are in good agreement with the calculated values. The deviation between the calculated and the experimental masses can be neglected.

PEG was chosen as a linker for two reasons. First, it protects the FLBP structure from outer water, oxygen and non-specific interior interactions, and increases the stability of FLBP in physiological conditions. Oxidised FLBP is not stable with PEG as indicated by positive adsorption energy values. Furthermore, the use of a non-ionic and hydrophilic linker can overcome the problem of nonspecific adsorption on the surface, e.g., by proteins from blood serum or a bioanalyte sample. Secondly, a stable immobilisation of peptides on a PEG linker prolongs circulation in the blood and prevents drug release during its transport, which may improve the pharmaceutical properties of the peptides.

\subsection{Ab-initio characterisation of FLBP surface with PEG and PLL}

The four layer model (two shown in Fig. 7) of the FLBP surface was elaborated as an optimal configuration to simulate the linker grafting efficiency and stability. The FLBP bandgap predicted with DFT was in agreement with prior literature results $(0.25 \mathrm{eV}){ }^{47,48}$. The PLL and PEG polymer linker bonding was simulated utilizing estimation of absorption energy on ideal pristine and defected oxidized FLBP (see Fig. 7). In order to simulate the atmospheric degradation of FLBP, we have saturated $50 \%$ of its surface with oxygen atoms as displayed in Fig. 7c,d. The simulated adsorption energies predicted for PLL and PEG are listed in Table 1.

The PLL molecule adsorption on pristine FLBP shows lower stability revealing the smallest adsorption energies required for its attachment. The attachment of PEG results in almost doubled values of adsorption energy in comparison to PLL. This fact is attributed to relatively large partial positive charge of the PEG chain amine group ${ }^{49}$. Simulations involving PEG adsorption display also relatively lower distances to the FLBP surface due to specific lateral stereochemical elongation. Moreover, the defected FLBP regions reveals much smaller distances to both PLL and PEG molecules since the intensive electrostatic interactions are induced by deprotonated $\mathrm{P}_{\mathrm{x}} \mathrm{O}_{\mathrm{y}}$ group simulated here as surficial oxygen. Nevertheless, the cationic PLL linker results also in a much larger negative adsorption energies caused by FLBP surface oxidation. It should be noted that adsorption of PEG at oxidized FLBP switches energies to large positive values suggesting suppression of positively charged PEG from a stable adsorption. 
Achieved results suggest that the polymer adsorption process would possess heterogenous behavior depending strongly on the FLBP surface quality, while it could be conducted effectively in the oxygen-free conditions.

Table 1

Results of simulation of adsorption energy for pristine FLBP and oxidised FLBP with PLL and PEG as linkers.

\begin{tabular}{|lll|}
\hline Substrate & PLL & PEG \\
\hline Pristine FLBP & $-3.92 \mathrm{kcal} \mathrm{mol}^{-1}$ & $-6.89 \mathrm{kcal} \mathrm{mol}^{-1}$ \\
\hline FLBP + oxygen & $-9.34 \mathrm{kcal} \mathrm{mol}^{-1}$ & $13.94 \mathrm{kcal} \mathrm{mol}^{-1}$ \\
\hline
\end{tabular}

Ab-initio simulation allows to conclude that PEG conjugates are more stable at the pristine FLBP than PLL conjugates as evidenced by a more negative adsorption value. Nonetheless, if the FLBP will be partially oxidized, PEG conjugates may not be effectively formed due to observed positive adsorption energy. This effect does not influence the FLBP-PLL-peptide procedure as the adsorption energy at oxidized FLBP is even more negative and generates more robust structure than pristine FLBP-PLLpeptide.

\subsection{Characterisation of structure and morphology of conjugates}

\subsubsection{TEM analysis}

The morphology of the obtained particulates was characterised by transmission electron microscopy (TEM) to quantify the shape, size and thickness. Representative TEM images of the samples (Fig. 8) revealed the presence of few-layered thin phosphorus flakes where the lateral size of the FLBP conjugates was around 200 nanometers.

\subsubsection{SEM}

SEM micrographs demonstrate that after functionalisation of FLBP by both polymers, the conjugates showed different morphologies than pristine FLBP (Fig. 9a). However, the surfaces of the FLBPs functionalised with PLL present a particle FLBP coated by PLL and peptide (Fig. 9d, e). SEM micrographs of the FLBP after PEGylation indicate a compact surface with visible bonded layers. These findings show that the structural differences depend on the linkers (PEG, PLL). The influence of the linkers is due to their structure and particularly to their charge. The non-ionic linker (PEG) forms interconnected layers (Fig. 9b, c), while the positively charged (PLL) repels the reaction products from each other and causes dispersion of the conjugates (Fig. 9d, e).

\subsubsection{Infrared analysis}


Infrared spectra confirm the formation of conjugates of the FLBP with the PLL or PEG and the peptides. Figure 10 shows the spectra of the bare FLBP as well as the FLBP-PLL-peptide and FLBP-PEG-peptide. Fourier transform infrared spectroscopy (FTIR) analysis was acquired from 4000 to $400 \mathrm{~cm}^{-1}$. The FTIR spectrum of the FLBP-PEG-peptide is characterised by a number of characteristic bands occurring in the ranges $3600-3300 \mathrm{~cm}^{-1}, 3100-2200 \mathrm{~cm}^{-1}, 1750-1550 \mathrm{~cm}^{-1}, 1550-1300 \mathrm{~cm}^{-1}$, and $1300-900 \mathrm{~cm}^{-1}$. The broad peak observed in the FLBP sample, and for the PEG conjugates at about $3400 \mathrm{~cm}^{-1}$ is attributed to the $-\mathrm{O}-\mathrm{H}$ stretching band, whereas the signal at about $1650 \mathrm{~cm}^{-1}$ corresponds to the $-\mathrm{O}-\mathrm{H}$ bending mode. It can be assumed that the black phosphorus contained moisture. In the case of the PEG conjugates, this peak is shifted towards lower frequencies, and it may originate from hydroxyl stretching vibration bands in the polymer.

For the FLBP and all conjugates, a transmittance peak was recorded at approximately $1150 \mathrm{~cm}^{-1}$ resulting from phosphorus oxidised during synthesis ( $\mathrm{P}-\mathrm{O}$ stretching). The bands at $3100-2500 \mathrm{~cm}^{-1}$ and $1550-1300 \mathrm{~cm}^{-1}$ correspond to stretching and bending vibrations of functional groups $\mathrm{CH}, \mathrm{CH}_{2}$, and $\mathrm{CH}_{3}$. The FLBP-PEG-peptide shows the characteristic narrow and intense C-O-C absorption band at 1112 $\mathrm{cm}^{-1}$ in the FTIR spectrum. The peak is absent for the FLBP and FLBP-PLL-peptide conjugates. Absorption bands in the region of $1300-900 \mathrm{~cm}^{-1}$ correspond to the presence of amino groups. In this region, there are also overlapping signals from $-\mathrm{P}-\mathrm{O}$ and $\mathrm{C}-\mathrm{O}-\mathrm{C}$ stretching vibrations. For PLL conjugates at 3304 and $3293 \mathrm{~cm}^{-1}$ for the KRK and RGD, respectively, there are visible peaks originating from the $\mathrm{N}$ $\mathrm{H}$ stretching band. The bands in the range $3200-2700 \mathrm{~cm}^{-1}$ are attributed to the $-\mathrm{O}-\mathrm{H}$ stretching of the carboxylic group which confirms the presence of PLL in the conjugate. Similar to the FLBP-PEG-peptide, the FLBP-PLL-peptide has regions at $3000-2500 \mathrm{~cm}^{-1}$ and $1460-1370 \mathrm{~cm}^{-1}$ which correspond to stretching and bending vibrations, respectively, of functional groups $\mathrm{CH}, \mathrm{CH}_{2}$, and $\mathrm{CH}_{3}$. Absorption bands in the region $1300-950 \mathrm{~cm}^{-1}$ correspond to the presence of amino groups.

The two regions corresponding to the presence of the peptides are the amide peaks. The more intense amide band $\left(1600-1700 \mathrm{~cm}^{-1}\right)$ is associated mainly with $\mathrm{C}=0$ stretching vibrations with major contributions from $\mathrm{C}-\mathrm{N}$ stretching. The less intense amide band $\left(1480-1580 \mathrm{~cm}^{-1}\right)$ originates from bending motions of the $\mathrm{N}-\mathrm{H}$ groups and stretching of the $\mathrm{C}-\mathrm{N}$ bonds of the peptide bonds. The other amide bands are less commonly used for peptide analysis. The problem in the spectral analysis of the peptides is that the widths of the various contributing bands are usually much greater than the peak separations ${ }^{50}$.

\subsubsection{Raman analysis}

In Fig. 11, the Raman spectra confirms the presence of black phosphorus in each tested conjugate. We have shown that a typical characteristic for few-layer black phosphorus is maxima near 357, 432, and $459 \mathrm{~cm}^{-1}$ for bare FLBP corresponding to the $A_{g}{ }^{1}, B_{2 g}$ and $A_{g}{ }^{2}$ modes, respectively. The relative band intensities in the Raman spectra recorded for the conjugates were shifted to 361,436 and $465 \mathrm{~cm}^{-1}$ for 
the $A_{g}{ }^{1}, B_{2 g}$, and $A_{g}{ }^{2}$ modes, respectively, which is related to the additional stresses associated with the connection of the FLBP surface with the polymer and peptide.

In the range $800-900 \mathrm{~cm}^{-1}$, abnormal peaks can be noticed. This is associated with the anisotropy of FLBP, and the literature shows a strong dependence on the azimuthal angle. It has been proven by Xi Ling et al. that these the newly anomalous phonon modes are caused by the resonant Raman effect ${ }^{51}$. The carbon-hydrogen stretching region ranges from 2800 to $3000 \mathrm{~cm}^{-1}$ and includes a series of overlapping vibrational bands correlated with the acyl group and overtones of the methylene deformation modes. The peaks are attributed to the methylene symmetric and asymmetric $\mathrm{C}-\mathrm{H}$ stretching vibrations ${ }^{52}$.

\subsection{Cytotoxicity of FLBP functionalisations}

To investigate the cytotoxic effects of FLBP and its modifications on breast cancer cell lines, MCF-7, MDA-MB-231 and HB2 cells were treated with increasing concentrations of PEG, KRK, RGD, PLL, FLBP, BPPEG-RGD, BP-PEG-KRK, BP-PLL-RGD, and BP-PLL-KRK $\left(0,0.8,4,20 \mathrm{mg} \mathrm{ml}^{-1}\right)$ for $72 \mathrm{~h}$. The MTT assay revealed cell- and dose-dependent cytotoxicity of FLBP and its modifications. HB2 (normal mammary cells) was affected only at the highest concentration of $\operatorname{FLBP}\left(20 \mu \mathrm{g} \mathrm{ml}^{-1}\right)$, whereas the viability of the MCF-7 and MDA-MB-231 breast cancer cells decreased at $4 \mathrm{\mu g} \mathrm{ml}^{-1}$. Comparing these two cancer cell lines, FLBP at a concentration of $4 \mu \mathrm{g} \mathrm{ml} /$ was more toxic to the aggressive cell line, MDA-MB-231 (38\% viability), than to MCF-7 (69\% viability). No components of the subsequent FLBP modifications showed toxicity (Fig. 12a). Modifications of FLBP with PEG-peptide seems to completely neutralise FLBP's toxicity in all tested cells. Even at the highest concentration, cell viability was more than $80 \%$ (Fig. 12b). Attaching PLL-peptide to FLBP resulted in reduced cytotoxicity, but only in normal mammary cells; HB2 cells exhibited $\sim 70 \%$ cell viability at $20 \mu \mathrm{g} \mathrm{ml}^{-1}$, while the cancerous cells were found to be more sensitive to this modification. In addition, this modification is more toxic to the triple-negative breast cancer cell culture - MDA-MB-231 (viability < 34\%) compared to the luminal breast cancer cell culture - MCF7 (viability $<46 \%$ ).

The biocompatibility of black phosphorus is unclear. Some studies show that BP has no cytotoxic effect on cells ${ }^{53-55}$, but none of them incubated this material with cells for longer than $48 \mathrm{~h}$. A more probable hypothesis is that the toxicity of black phosphorus is dependent on the time, dose and tested cell type 55,56 , which is in agreement with our results. The cytotoxicity of FLBP is most likely due to membrane disruption and oxidative stress-mediated metabolic activity reduction ${ }^{57,58}$. The biocompatibility and stability of BP may be improved by its modification and packaging ${ }^{10,59}$.. PEG, which has gained FDA approval, has been widely used in various biomedical fields due to its biocompatibility and hydrophilicity, it was shown that PEGylation can improve water-stability of drugs ${ }^{60}$. Here we observed that conjugation of PEG-peptide abolished the toxicity in all tested cells, suggesting that this modification could be implemented as a therapeutic delivery carrier. Conjugates FLBP-PLL-peptide was also neutral for normal mammary cells but exhibited strong toxicity to breast cancer cell lines. It could have been due to the fact that PLL, cationic polymer, has slightly worse biocompatibility than PEG, it can induce apoptosis by 
damaging cell membrane ${ }^{61,62}$. Our results show that PLL itself is neutral for all tested cells but toxicity of PLL conjugated with KRK and RGD is cancer cells specific. This suggests that KRK and RGD motifs have great potential for targeting tumor cells and applying FLBP-PLL-peptide for cancer treatments could enhance the cytotoxic effect of cancer drugs.

\section{Conclusions}

Summarizing, we have successfully conducted two novel functionalisation procedures resulting in fabrication of FLBP-PEG and FLBP-PLL tumor-homing peptide conjugates. PEG and PLL were critically compared as a spacer molecules due to their different polymer masses, structures and cytotoxic activity. The effects were demonstrated using in vitro experiments.

Both TEM and SEM micrographs demonstrated shaped typical for functionalised FLBP by polymers revealing conjugates of 200 nanometers with in contrast to pristine FLBP. Raman proved the stability of functionalised FLBP, while FT-IR studies confirmed both spacer and peptides grafting.

The experimental data were supported by ab-initio model manifesting that PEG-peptide adsorption is favored at the pristine FLBP. Interestingly, the partially oxidized FLBP still allows for an efficient PLLpeptide adsorption in contrast the suppression of PEG molecules due to the deprotonated $\mathrm{P}_{\mathrm{x}} \mathrm{O}_{\mathrm{y}}$ surficial groups. Data showed that polymer adsorption process would reveal specific heterogenous behavior depending on the FLBP surface termination.

FLBP exhibited different levels of toxicity depending on its concentration, type of modification and the tested cell line. Functionalisation of FLBP with PLL reduced cytotoxicity in normal mammary cells but was toxic to cancerous cells, especially to the triple-negative breast cancer cell culture - MDA-MB-231. These findings suggest that applying FLBP-PLL as a therapeutic delivery carrier for cancer treatments could enhance the cytotoxic effect of cancer drugs, although further comprehensive studies are necessary to understand the mechanism of its toxic effects. Proposed functionalisation by decoration surface of FLBP with polymeric micelles allowed to tune its biocompatibility, degradability and drug loading ability for controlled and targeted anticancer drug delivery therapies. The non-ionic and hydrophilic linkers overcome the problem of non-specific adsorption on the FLBP surface, e.g., by proteins from blood serum or a bioanalyte sample. Next, the stable immobilisation of peptides on a PEG linker prolongs circulation in the blood and prevents drug release during its transport.

\section{Declarations}

\section{Conflict of interest}

There are no conflicts to declare.

\section{Author Information}


ORCID

P. Jakóbczyk: 0000-0002-6528-3713

M. Biedulska: 0000-0002-0659-7659

B. Dec: 0000-0001-5103-2000

R. Bogdanowicz: 0000-0002-7543-2620

A. J. Zaczek: 0000-0003-1482-6068

A. Muchlińska: 0000-0001-5886-4854

M. Sosnowska: 0000-0001-8196-1791

\section{Acknowledgment}

This work was supported by the Polish National Science Centre [2016/22/E/ST7/00102] and [2015/17/ST5/02571]. The DS funds of the Faculty of Electronics, Telecommunications and Informatics of the Gdansk University of Technology are also acknowledged.

\section{References}

1. Novoselov, K. S. et al. A. A. F. Electric Field Effect in Atomically Thin Carbon Films. Science (80-). 306, 666-669 (2004).

2. Chen, P., Li, N., Chen, X., Ong, W. J. \& Zhao, X. The rising star of 2D black phosphorus beyond graphene: Synthesis, properties and electronic applications.2D Mater. 5, (2018).

3. Society, A. C., Xie, L. \& Wu, J. Optical Anisotropy of Black Phosphorus in the. (2015). doi:10.1021/jacs.5b10685

4. Shao, L. et al. Facile preparation of $\mathrm{NH} 2$-functionalized black phosphorene for the electrocatalytic hydrogen evolution reaction. J. Mater. Chem. A. 6, 2494-2499 (2018).

5. Tao, Y. et al. Few-layer phosphorene: An emerging electrode material for electrochemical energy storage. Appl. Mater. Today. 15, 18-33 (2019).

6. Jiang, J. \& Park, H. S.Mechanical properties of single-layer black phosphorus.385304,14-17

7. Tang, H. et al. Progress in Natural Science: Materials International MXene - 2D layered electrode materials for energy storage. Prog. Nat. Sci. Mater. Int. 28, 133-147 (2018).

8. Das, S. et al. Tunable Transport Gap in Phosphorene. Nano Lett. 14, 5733-5739 (2014).

9. Torbatian, Z. \& Asgari, R. PHYSICAL REVIEW B 98, 205407(2018) Optical absorption properties of few-layer phosphorene. 205407, 1-9 (2018).

10. Sun, C. et al. One-pot solventless preparation of PEGylated black phosphorus nanoparticles for photoacoustic imaging and photothermal therapy of cancer. Biomaterials. 91, 81-89 (2016). 
11. Liang, X. et al. Photothermal cancer immunotherapy by erythrocyte membrane-coated black phosphorus formulation. J. Control. Release. 296, 150-161 (2019).

12. Kang, T. H., Lee, S., Kwon, J. A., Song, J. \& Choi, I. Photothermally Enhanced Molecular Delivery and Cellular Positioning on Patterned Plasmonic Interfaces. ACS Appl. Mater. Interfaces. 11, 3642036427 (2019).

13. Hashemzadeh, H. \& Raissi, H. Loading and release of anticancer drug from phosphorene as a template material with high efficient carrier: From vacuum to cell membrane. J. Mol. Liq. 291, 111346 (2019).

14. Jakóbczyk, P. et al. Low-power microwave-induced fabrication of functionalised few-layer black phosphorus electrodes: A novel route towards Haemophilus Influenzae pathogen biosensing devices. Appl. Surf. Sci. 539, 148286 (2021).

15. Kim, J., Sando, S. \& Cui, T. Biosensor based on layer by layer deposited phosphorene nanoparticles for liver cancer detection. ASME Int. Mech. Eng. Congr. Expo. Proc. 2, 1-6(2017).

16. Murugan, C., Sharma, V., Murugan, R. K., Malaimegu, G. \& Sundaramurthy, A. Two-dimensional cancer theranostic nanomaterials: Synthesis, surface functionalization and applications in photothermal therapy. J. Control. Release. 299, 1-20 (2019).

17. Imaging, P. E. T. et al. Pegylated Arg-Gly-Asp Peptide: 64 Cu Labeling Expression. 45, 1776-1783 (2004).

18. Zhao, Y. et al. Synthesis of a Poly - . (2018). doi:10.1021/acs.analchem.7b04395

19. Banerjee, S. S., Aher, N., Patil, R. \& Khandare, J. Poly (ethylene glycol) -Prodrug Conjugates: Concept, Design, and Applications 2012, (2012).

20. Cui, Y. Black Phosphorus-Based Drug Nanocarrier for Targeted and Synergetic Chemophotothermal Therapy of Acute Lymphoblastic Leukemia. (2019). doi:10.1021/acsami.8b22563

21. Wu, F. et al. Black phosphorus nanosheets-based nanocarriers for enhancing chemotherapy drug sensitiveness via depleting mutant p53 and resistant cancer multimodal therapy. Chem. Eng. J. 370, 387-399 (2019).

22. Miller, J. S. et al. Biomaterials Bioactive hydrogels made from step-growth derived PEG - peptide macromers. Biomaterials. 31, 3736-3743 (2010).

23. Guerrini, L. \& Alvarez-puebla, R. A. \& Pazos-perez, N. Surface Modifications of Nanoparticles for Stability in Biological Fluids.1-28(2018). doi:10.3390/ma11071154

24. Shen, W. C. \& Ryser, H. J. P. Poly(l-lysine) and poly(d-lysine) conjugates of methotrexate: different inhibitory effect on drug resistant cells. Mol. Pharmacol. 16, 614-622 (1979).

25. Shen, H. J. P. R. W.-C. Conjugation of methotrexate to poly(L-lysine) increases drug transport and overcomes drug resistance in cultured cells. Proc. Natl. Acad. Sci. USA 75, 3867-3870(1978).

26. Chiou, H. C. et al. Enhanced resistance to nuclease degradation of nucleic acids complexed to asialoglycoprotein-polylysine carriers. 22,5439-5446(1994).

27. Northover, A. Gene transfer therapy in cancer. 80, 566-572 (1993). 
28. Nanobiotechnol, J. et al. Smart nanoplatform for sequential drug release and enhanced chemo thermal effect of dual drug loaded gold nanorod vesicles for cancer therapy. J. Nanobiotechnology. 1-15, https://doi.org/10.1186/s12951-019-0473-3 (2019).

29. Wan, S., Zhang, B., Li, S. \& Pu, Y. Combination of PEG-decorated black phosphorus nanosheets and immunoadjuvant. (2020). doi:10.1039/d0tb00434k

30. Kim, K., Lee, J., Kim, D. \& Yoon, I. Recent Progress in the Development of Poly (lactic- co -glycolic acid) -Based Nanostructures for Cancer Imaging and Therapy.

31. Pisal, D. S., Kosloski, M. P. \& Balu-iyer, S. V. Delivery of Therapeutic Proteins. 99, 2557-2575 (2010).

32. Yavari, B., Mahjub, R., Saidijam, M., Raigani, M. \& Soleimani, M. The Potential Use of Peptides in Cancer Treatment.1-12(2018). doi:10.2174/1389203719666180111150008

33. Lieber, D. S., Elemento, O. \& Tavazoie, S. Large-scale discovery and characterization of protein regulatory motifs in eukaryotes.PLoS One5, (2010).

34. Rathore, S. S. et al. Intracellular Vesicle Fusion Requires a Membrane-Destabilizing Peptide Located at the Juxtamembrane Region of the v-SNARE. Cell Rep. 29, 4583-45923 (2019).

35. Hoffman, J. A. et al. Progressive vascular changes in a transgenic mouse model of squamous cell carcinoma. Cancer Cell. 4, 383-391 (2003).

36. Yao, X. L. et al. Optimization and internalization mechanisms of PEGylated adenovirus vector with targeting peptide for cancer gene therapy. Biomacromolecules. 13, 2402-2409 (2012).

37. Craggs, G., Kellie, S. A. \& Functional Nuclear Localization Sequence in the C-terminal Domain of SHP1. J. Biol. Chem. 276, 23719-23725 (2001).

38. Agemy, L. et al. Targeted nanoparticle enhanced proapoptotic peptide as potential therapy for glioblastoma. Proc. Natl. Acad. Sci. U. S. A. 111, 11906(2014).

39. Majumder, P. Integrin-mediated delivery of drugs and nucleic acids for anti-angiogenic cancer therapy: Current landscape and remaining challenges.Bioengineering5, (2018).

40. Kang, B., Mackey, M. A. \& El-Sayed, M. A. Nuclear targeting of gold nanoparticles in cancer cells induces DNA damage, causing cytokinesis arrest and apoptosis. J. Am. Chem. Soc. 132, 1517-1519 (2010).

41. Smidstrup, S. et al. QuantumATK: An integrated platform of electronic and atomic-scale modelling tools.J. Phys. Condens. Matter32, (2020).

42. Perdew, J. P., Burke, K. \& Ernzerhof, M. Generalized gradient approximation made simple. Phys. Rev. Lett. 77, 3865-3868 (1996).

43. Morita, A. Semiconducting black phosphorus. Appl. Phys. A Solids Surfaces. 39, 227-242 (1986).

44. Takao, Y., Asahina, H. \& Morita, A. Electronic Structure of Black Phosphorus in Tight Binding Approach. J. Phys. Soc. Japan. 50, 3362-3369 (1981).

45. Morga, M., Adamczyk, Z., Gödrich, S. \& Oc, M. Journal of Colloid and Interface Science Monolayers of poly- L -lysine on mica -. Electrokinetic characteristics. 456, 116-124 (2015). 
46. Sauer, B. B., Kampert, W. G., Mclean, R. S. \& Monteiro, R. Thermal Properties and Influence of Orientation on Crystalline Morphologies in Stereoblock Polypropylene and Related Elastomers.222243(2011). doi:10.1002/polb.22163

47. Tran, V., Fei, R. \& Yang, L. Quasiparticle energies, excitons, and optical spectra of few-layer black phosphorus.2D Mater.2, (2015).

48. Liang, L. et al. Electronic bandgap and edge reconstruction in phosphorene materials. Nano Lett. 14, 6400-6406 (2014).

49. Sun, H., Jiang, C., Wu, L., Bai, X. \& Zhai, S. Cytotoxicity-Related Bioeffects Induced by Nanoparticles: The Role of Surface Chemistry. Front. Bioeng. Biotechnol. 7, 1-22 (2019).

50. Bakshi, K., Liyanage, M. R., Volkin, D. B. \& Middaugh, C. R. Chapter 18 Fourier Transform InfraredSpectroscopy of Peptides.1088,255-269

51. Wang, X., Mao, N., Luo, W., Kitadai, H. \& Ling, X. Spectroscopy and Photochemistry; General Theory Anomalous Phonon Modes in Black Phosphorus Revealed by Resonant Raman Scattering Anomalous Phonon Modes in Black Phosphorus Revealed by Resonant Raman Scattering. (2018). doi:10.1021/acs.jpclett.8b01098

52. Carrier, D., Pezolet, M., RAMAN SPECTROSCOPIC STUDY OF \& THE INTERACTION OF POLY-L-LYSINE WITH.497-506(1978). doi:10.1016/S0006-3495(84)84047-3

53. Qiu, M. et al. Novel concept of the smart NIR-light-controlled drug release of black phosphorus nanostructure for cancer therapy. Proc. Natl. Acad. Sci. U. S. A. 115, 501-506(2018).

54. Chen, W. et al. Black Phosphorus Nanosheet-Based Drug Delivery System for Synergistic Photodynamic/Photothermal/Chemotherapy of Cancer. Adv. Mater. 29, 1-7 (2017).

55. Wang, M. et al. Ultrasmall black phosphorus quantum dots: synthesis, characterization, and application in cancer treatment. Analyst. 143, 5822-5833 (2018).

56. Song, S. J. et al. Comparison of cytotoxicity of black phosphorus nanosheets in different types of fibroblasts. Biomater. Res. 23, 1-7 (2019).

57. Song, S. J. et al. Dose-and time-dependent cytotoxicity of layered black phosphorus in fibroblastic cells. Nanomaterials. 8, 9-13 (2018).

58. Mu, X. et al. Black Phosphorus Quantum Dot Induced Oxidative Stress and Toxicity in Living Cells and Mice. ACS Appl. Mater. Interfaces. 9, 20399-20409 (2017).

59. Li, Y., Feng, P., Wang, C., Miao, W. \& Huang, H. Black phosphorus nanophototherapeutics with enhanced stability and safety for breast cancer treatment. Chem. Eng. J. 400, 125851 (2020).

60. Liu, Z., Robinson, J. T., Sun, X. \& Dai, H. PEGylated nanographene oxide for delivery of water-insoluble cancer drugs. J. Am. Chem. Soc. 130, 10876-10877 (2008).

61. Liu, X. Y., Nothias, J. M., Scavone, A., Garfinkel, M. \& Millis, J. M. Biocompatibility investigation of polyethylene glycol and alginate-poly-l-lysine for islet encapsulation. ASAIO J. 56, 241-245 (2010).

62. Jeong, H. et al. In vitro blood cell viability profiling of polymers used in molecular assembly. Sci. Rep. 7, 1-13 (2017). 


\section{Figures}

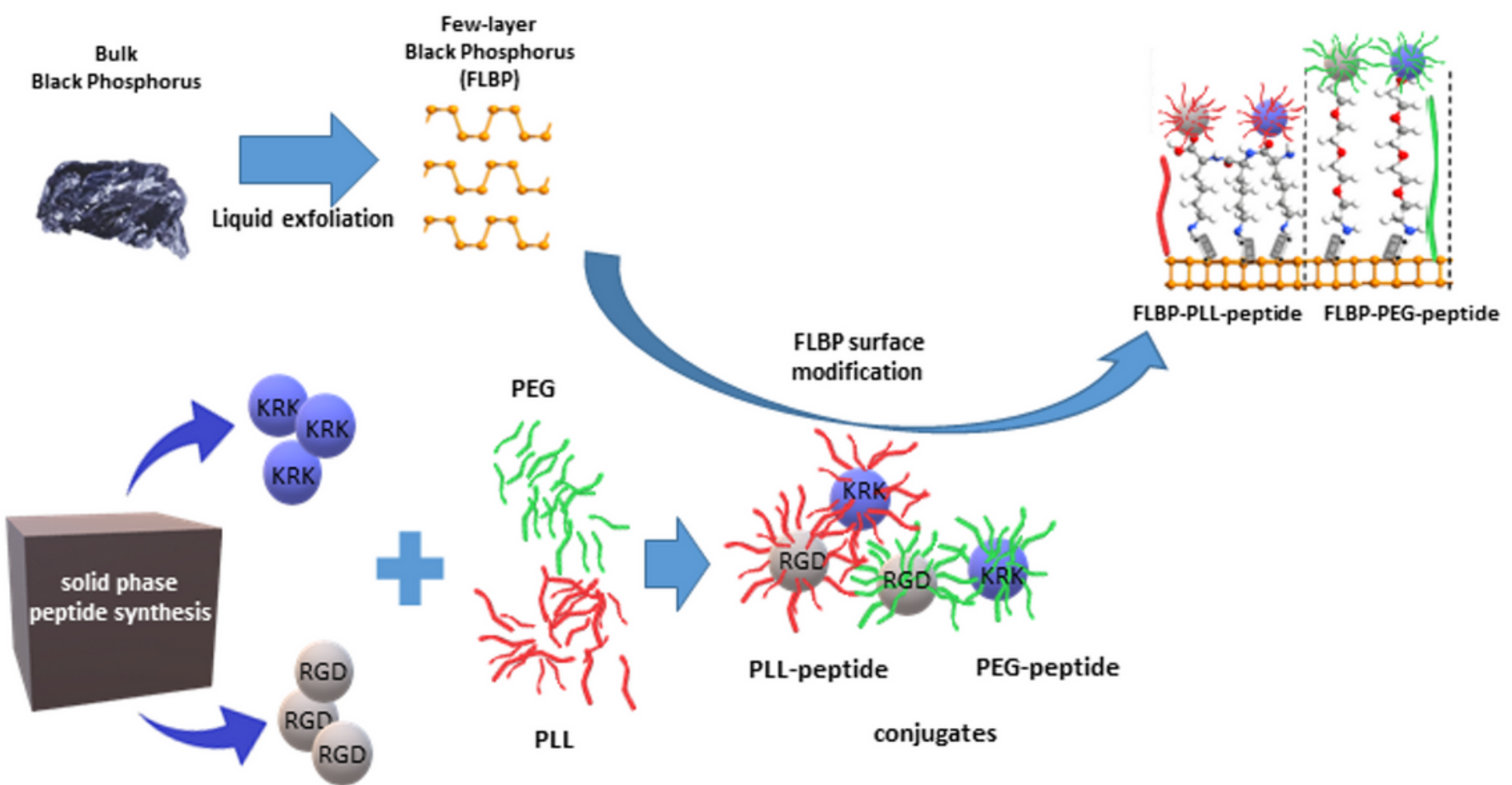

Figure 1

Scheme processes to yield FLBP-linker-peptide conjugates. 


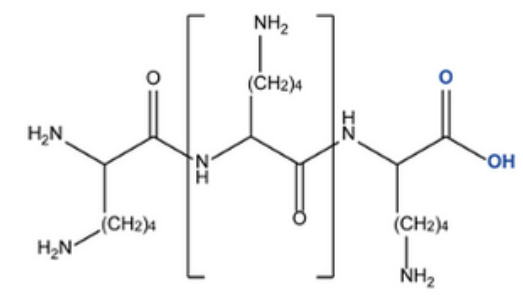

Poly-L-lysine (PLL)
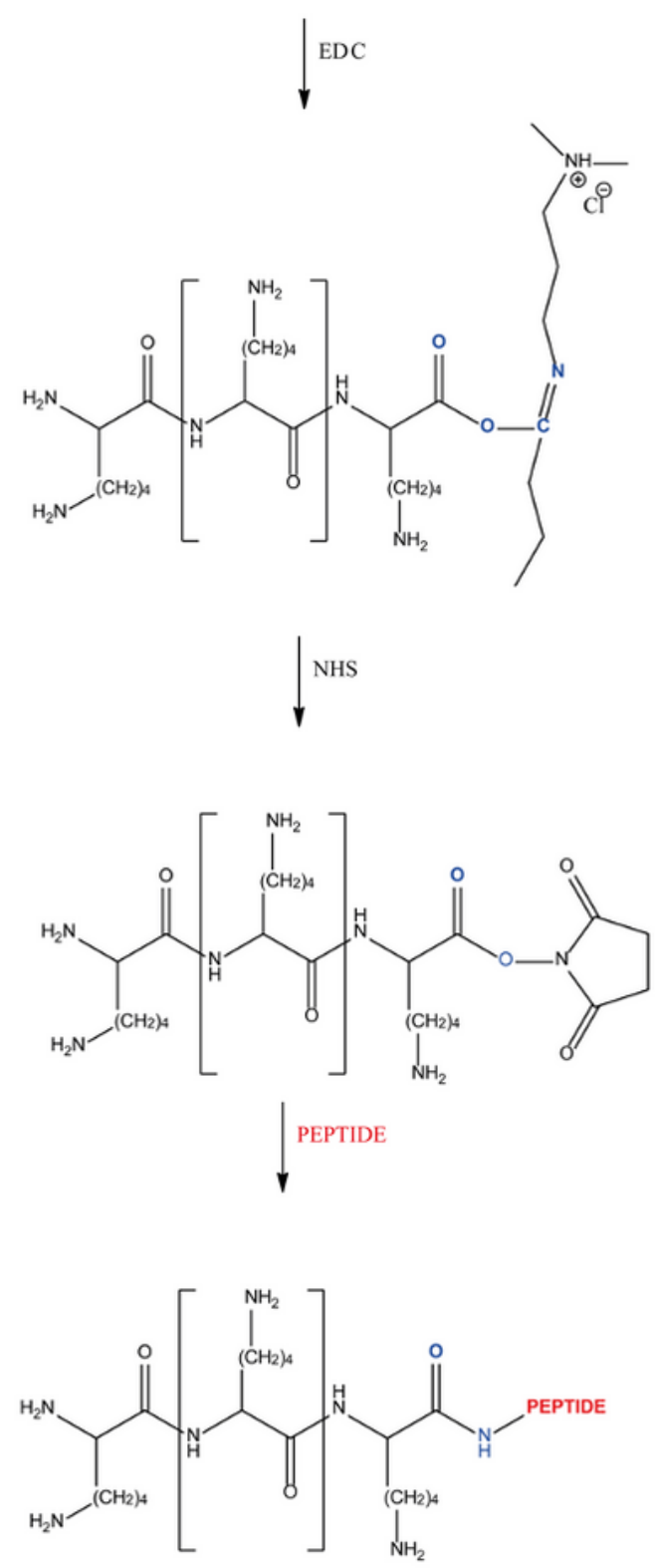

\section{Figure 2}

Linker (poly-L-lysine) is bound to a peptide through a EDC/NHS carbodiimide coupling reaction. Active ester was created from a carboxyl group of PLL. Primary amine group of selected peptide reacts and covalently binds to reactive ester. 

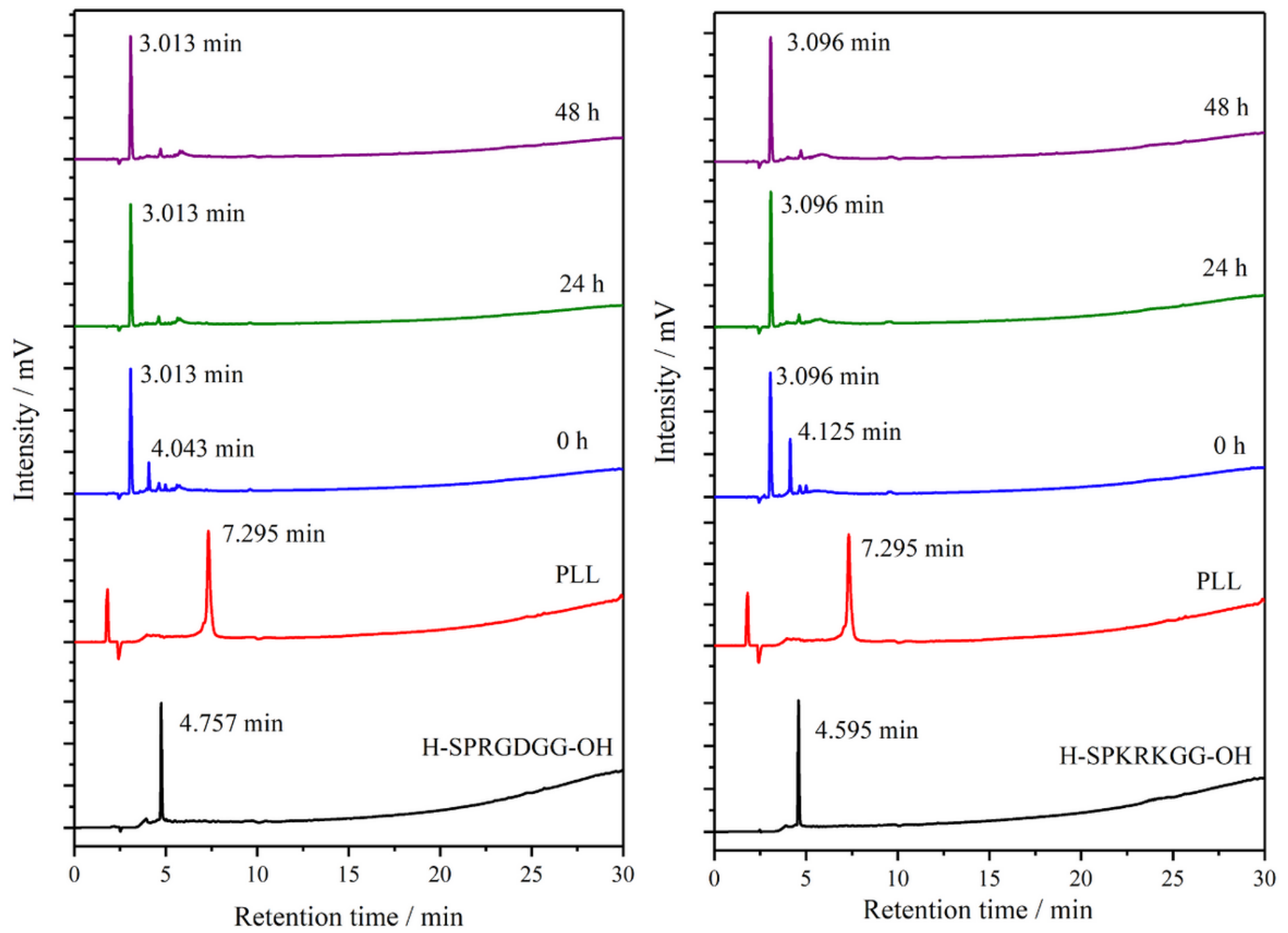

\section{Figure 3}

Covalent bioconjugation of PLL linker with RGD and KRK peptide reaction progress monitored by Reversed Phase High Performance Liquid Chromatography. RP-HPLC conditions: HPLC Shimadzu system (Shimadzu Prominence-i LC-2030C) with Cosmosil C18 column ( $4.60 \mathrm{~mm} \times 250 \mathrm{~mm}, 90 \AA .5 \mu \mathrm{m})$ using linear gradient method from 0 to $100 \%$ solvent $B$ for 30 min at flow rate of $1.50 \mathrm{~mL}$ min-1 with UV detection at $\lambda 1=224 \mathrm{~nm}$ and $\lambda 2=254 \mathrm{~nm}$. 


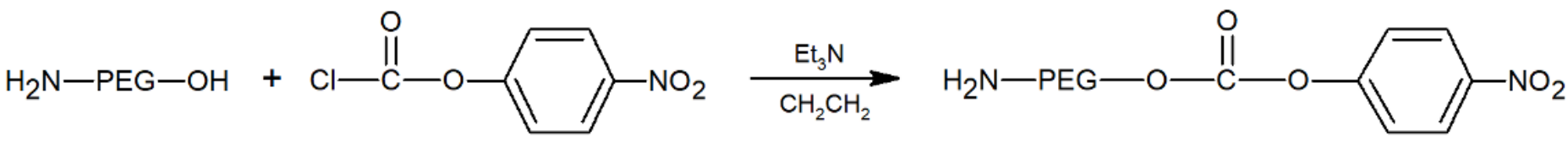

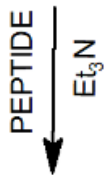

$$
\begin{aligned}
& \mathrm{H}_{2} \mathrm{~N}-\mathrm{PEG}-\mathrm{O}-\mathrm{O}-\mathrm{O}-\mathrm{NH}-\mathrm{PEPTIDE}-\mathrm{OH}
\end{aligned}
$$

\section{Figure 4}

Linker (hydroxy terminated PEG) is activated to PEG-p-nitrophenyl carbonate. In the next step, peptides are PEGylated by reacting with PEG-p-nitrophenyl carbonate and produce PEG-peptide conjugates.
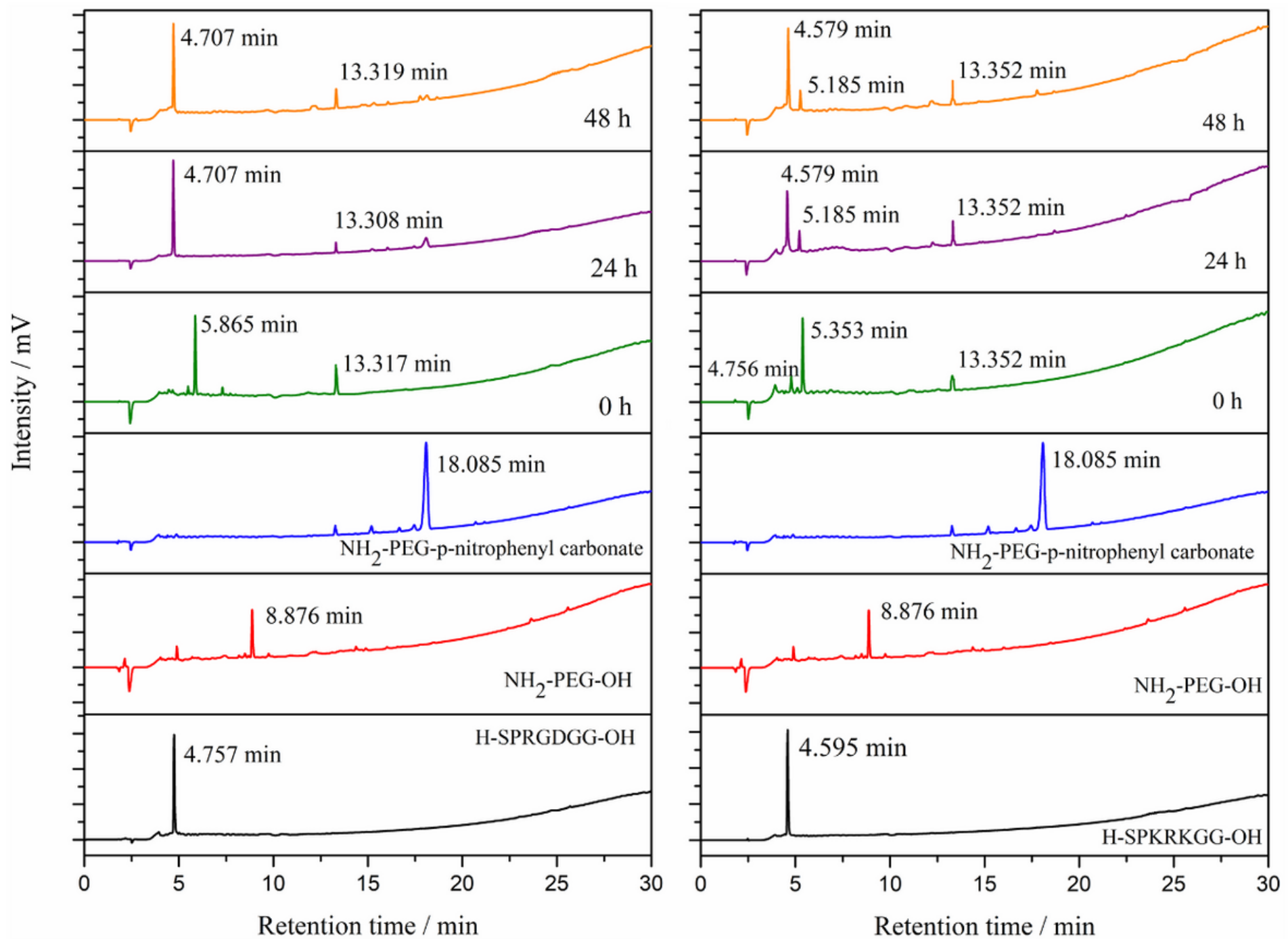

Figure 5 
Covalent bioconjugation of PEG linker with RGD and KRK peptides' reaction progress monitored by Reversed Phase High Performance Liquid Chromatography. RP-HPLC conditions: HPLC Shimadzu system (Shimadzu Prominence-i LC-2030C) with Cosmosil C18 column (4.60 mm×250 mm, $90 \AA$, $5 \mu \mathrm{m})$ using linear gradient method from 0 to $100 \%$ solvent $B$ for 30 min at a flow rate of $1.50 \mathrm{~mL}$ min-1 with UV detection at $\lambda 1=224 \mathrm{~nm}$ and $\lambda 2=254 \mathrm{~nm}$.
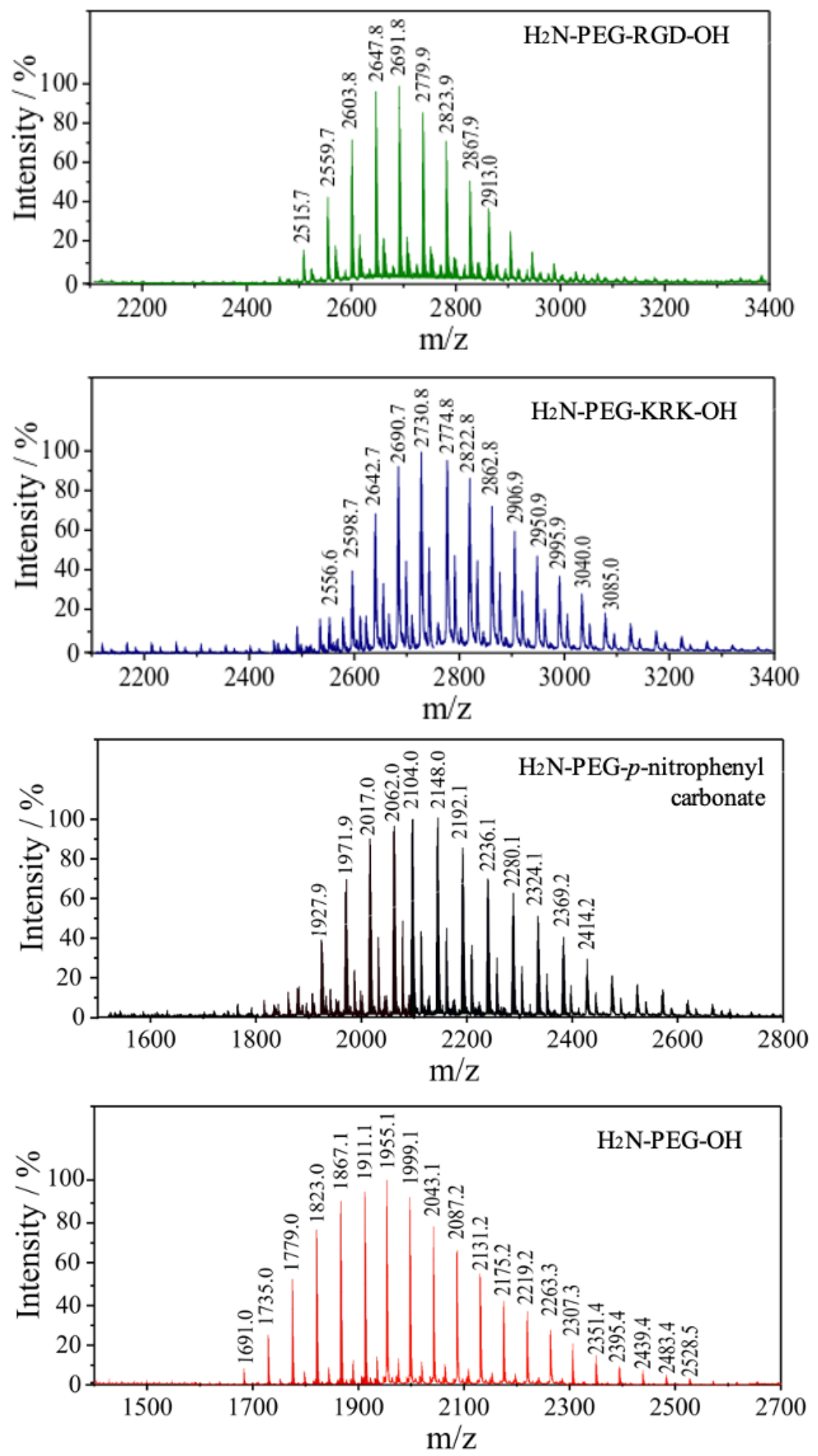

Figure 6 
MALDI-TOF mass spectra of: native H2N-PEG-OH polymer, activated H2N-PEG-p-nitrophenyl carbonate, H2N-PEG-RGD-OH conjugate, H2N-PEG-KRK-OH conjugate.

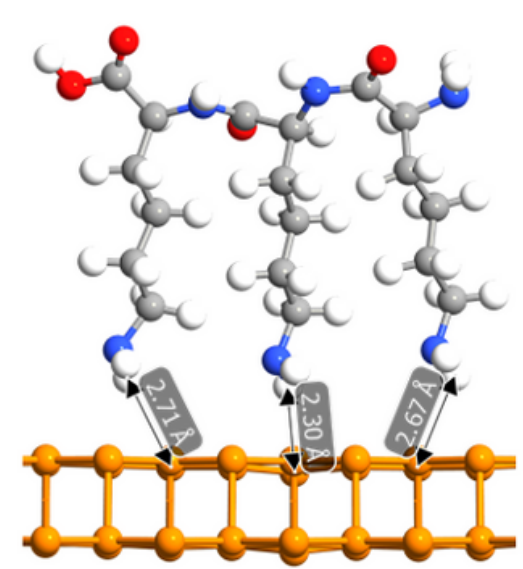

A) FLBP + PLL
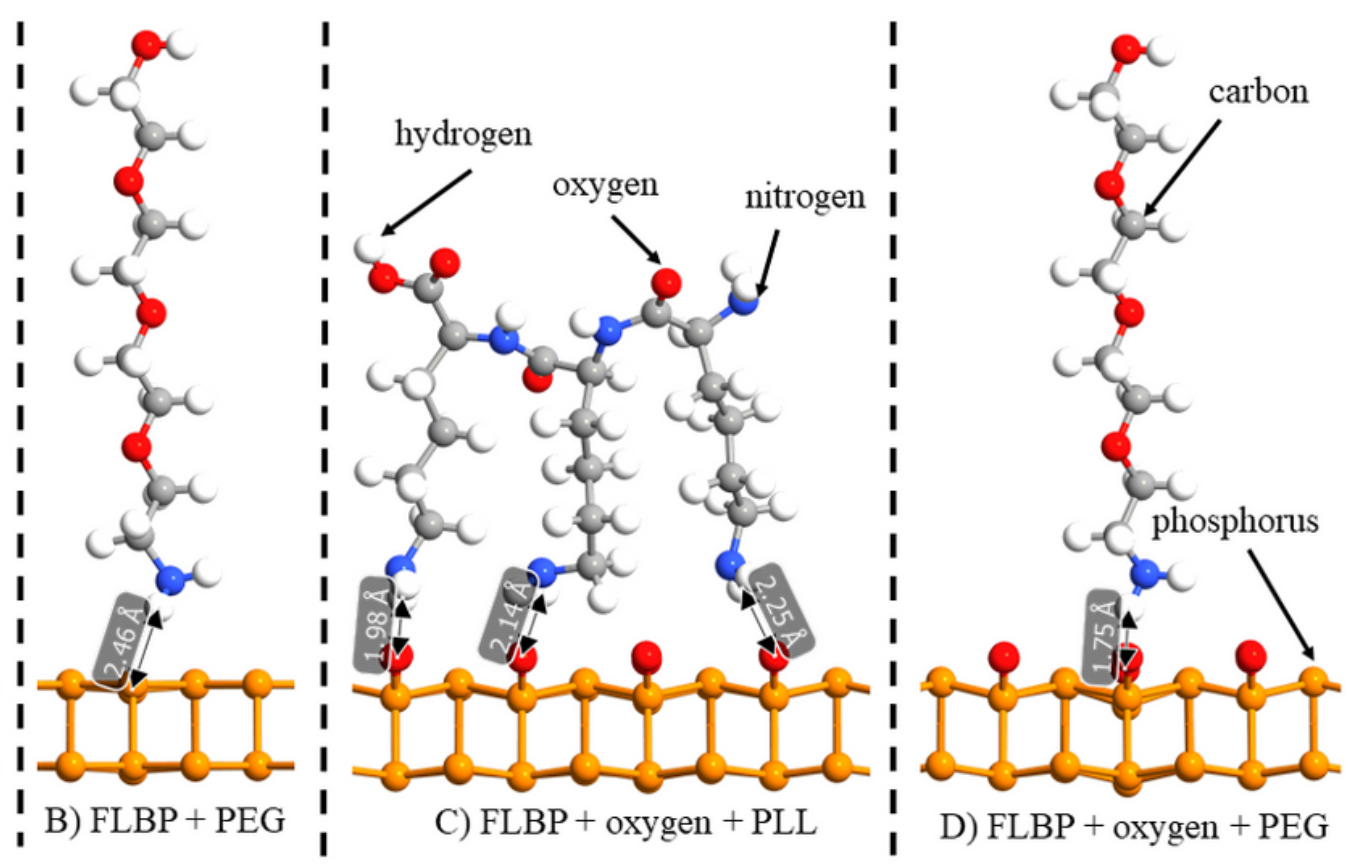

Figure 7

Oxidised and non-oxidised surfaces of FLBP with different linkers: a) non-oxidised with PLL, b) nonoxidised with PEG, c) oxidised with PLL and d) oxidised with PEG as linker. 
b)

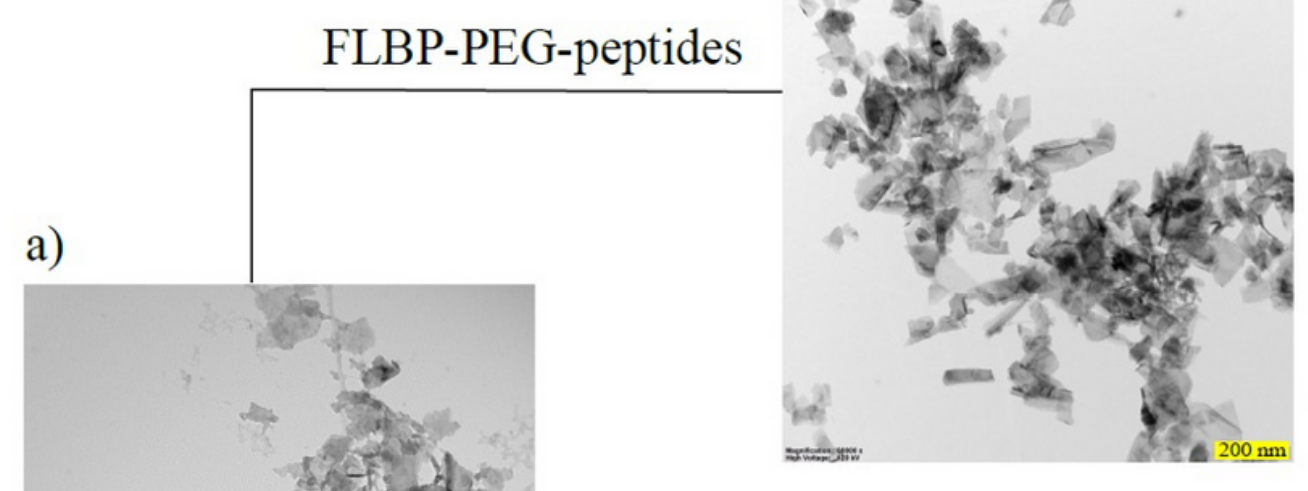

d)

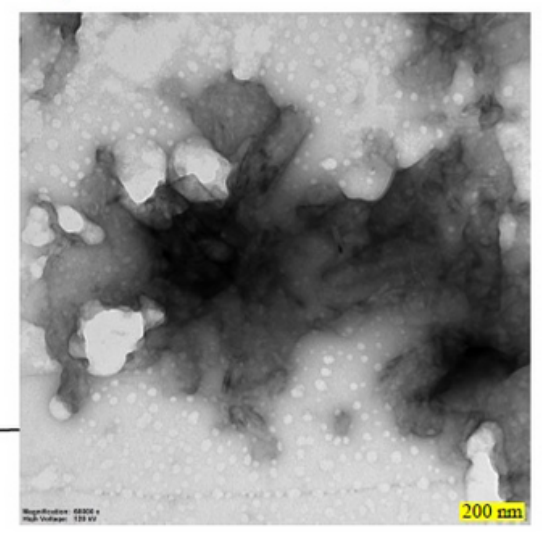

c)

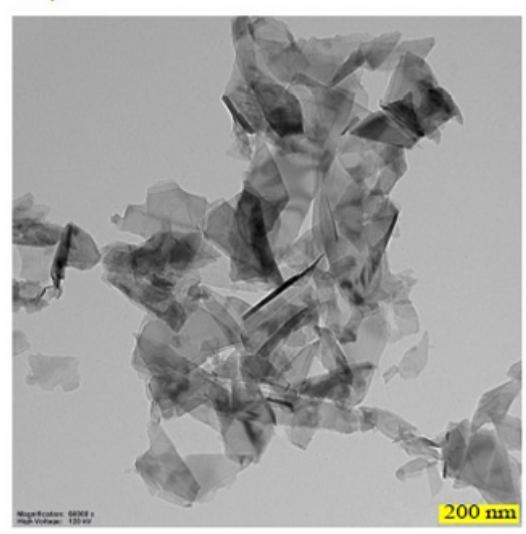

e)

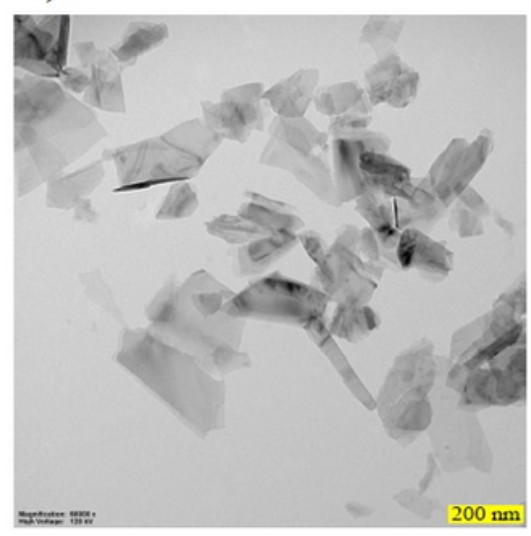

\section{Figure 8}

Transmission electron microscopy of exfoliated and functionalised black phosphorus nanoparticles: a) FLBP, b) FLBP-PEG-KRK, c) BP-PEG-RGD, d) FLBP-PLL-KRK, d) FLBP-PLL-RGD. 
b)

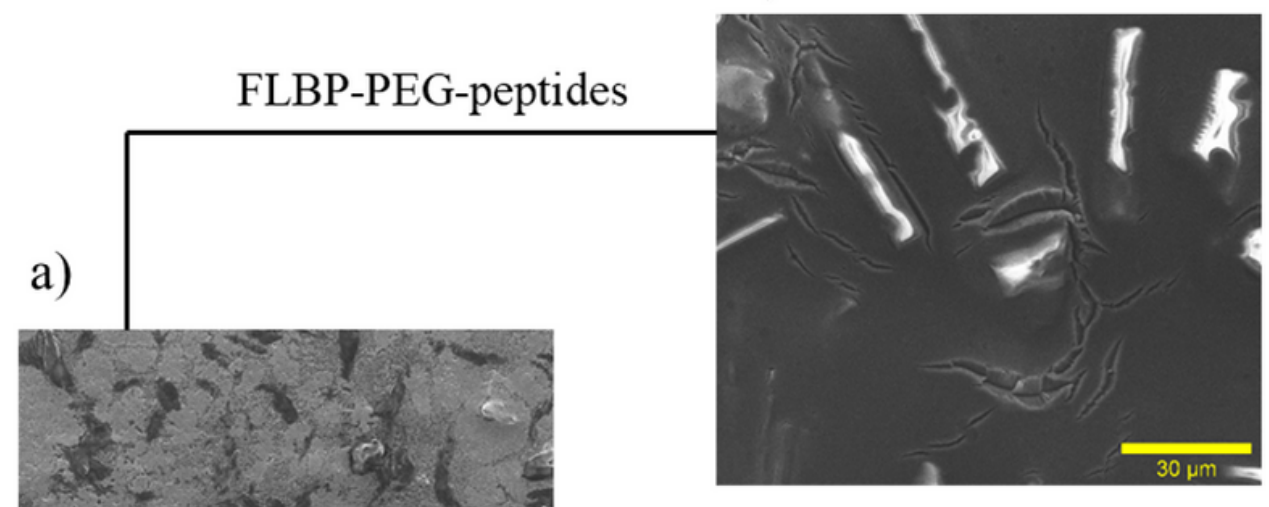

d)

FLBP-PLL-peptides c)

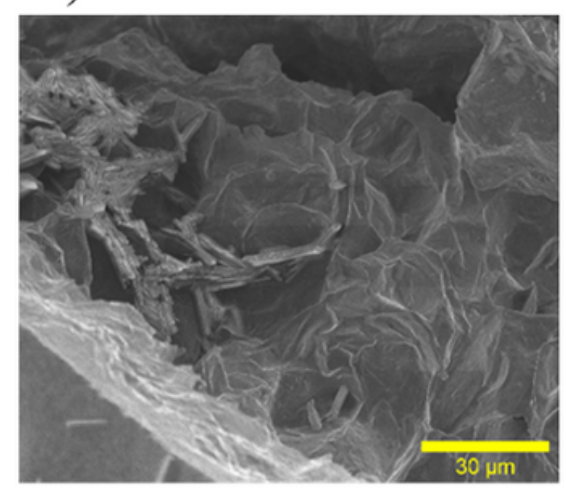

e)

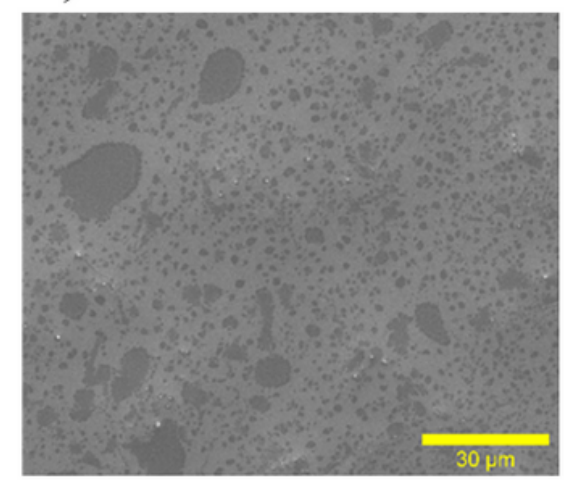

\section{Figure 9}

Scanning electron microscopy before and after functionalisation of FLBP: a) FLBP, b) FLBP-PEG-KRK, c) FLBP-PEG-RGD, d) FLBP-PLL-KRK, d) FLBP-PLL-RGD. 


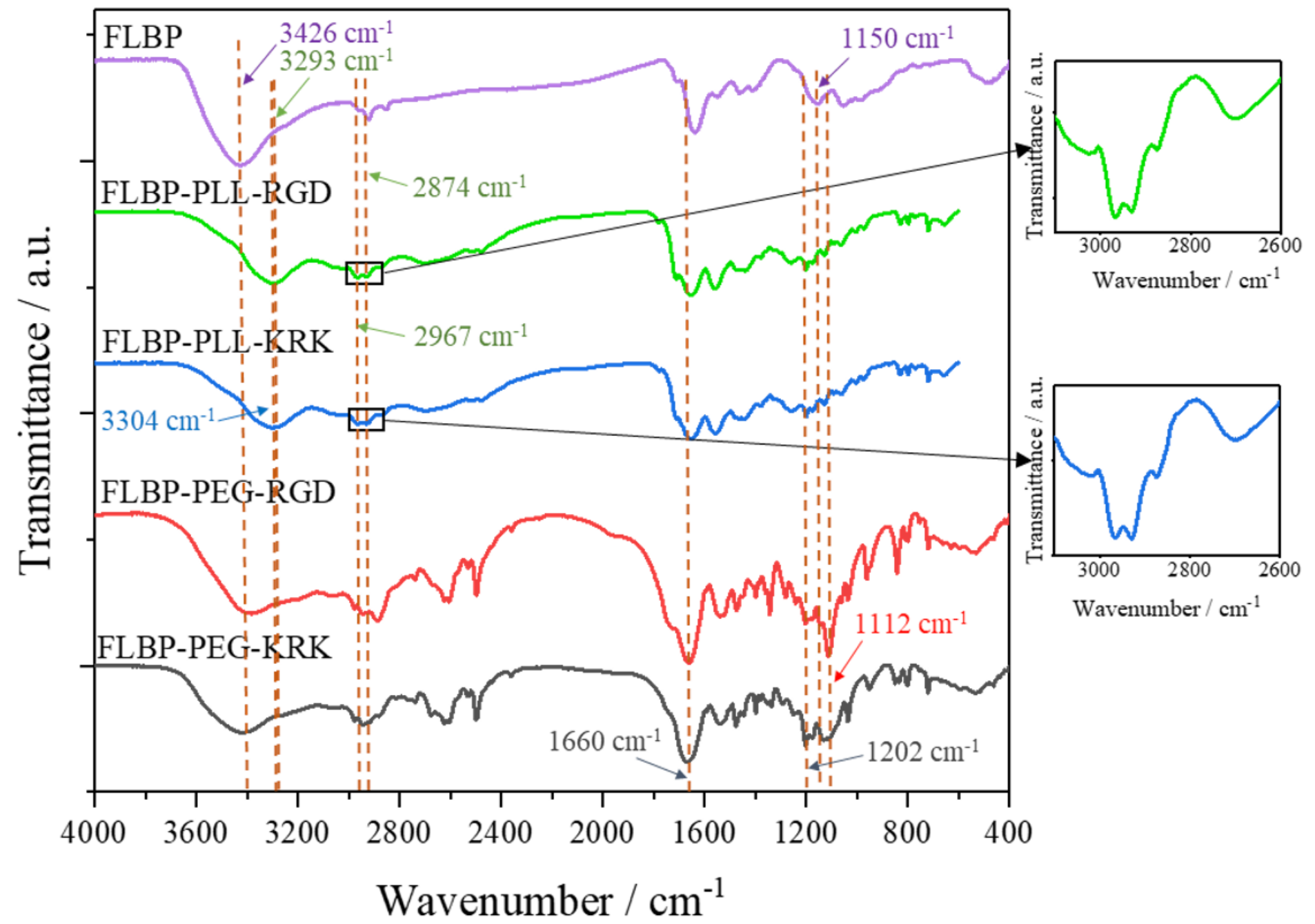

Figure 10

Fourier-transform infrared (FTIR) spectra for few layer black phosphorus (FLBP) and its conjugates: FLBP-PLL-RGD, FLBP-PLL-KRK, FLBP-PEG-RGD and FLBP-PEG-KRK. 


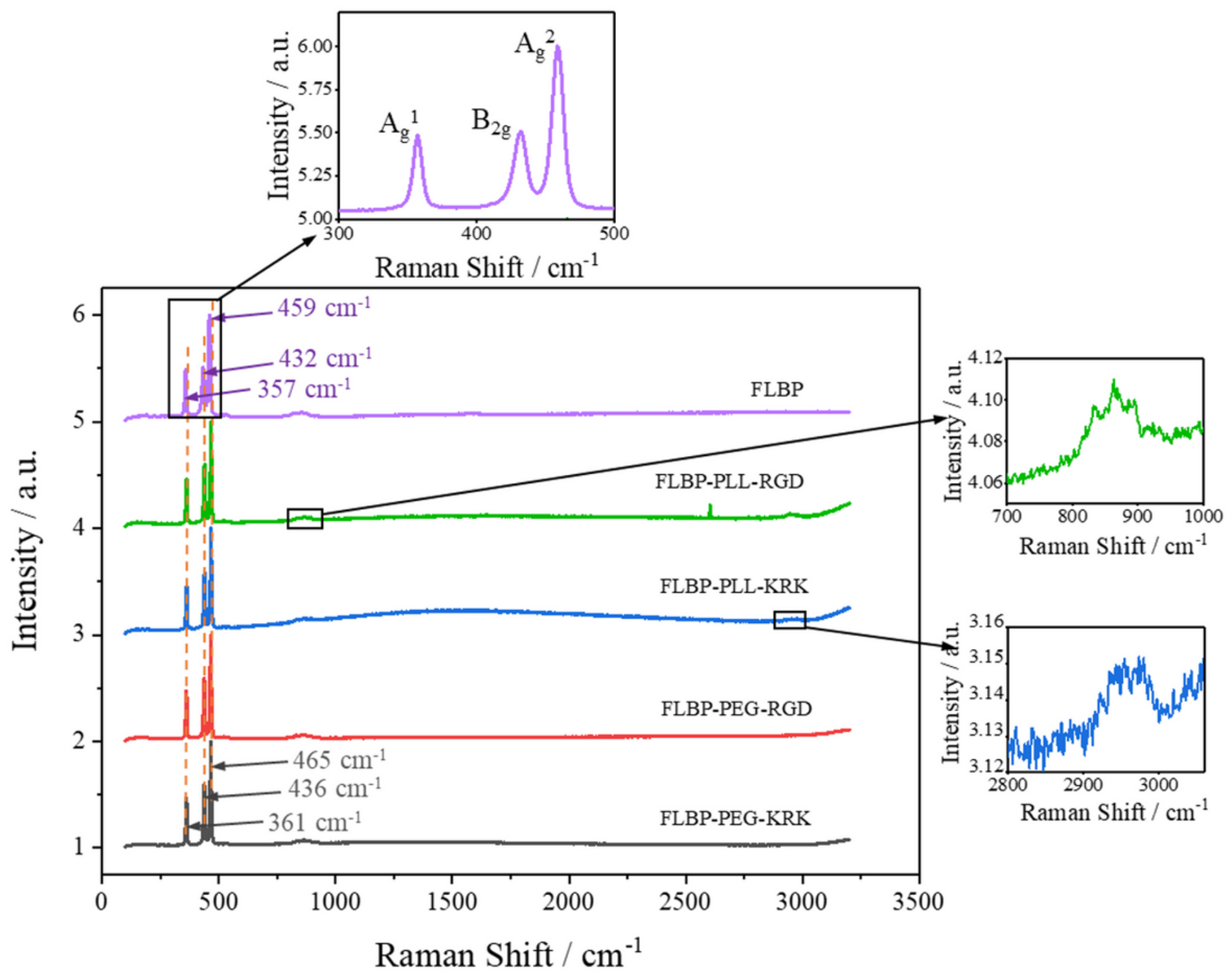

Figure 11

Raman spectra for few layer black phosphorus (FLBP) and its conjugates: FLBP-PLL-RGD, FLBP-PLLKRK, FLBP-PEG-RGD and FLBP-PEG-KRK. 
a)

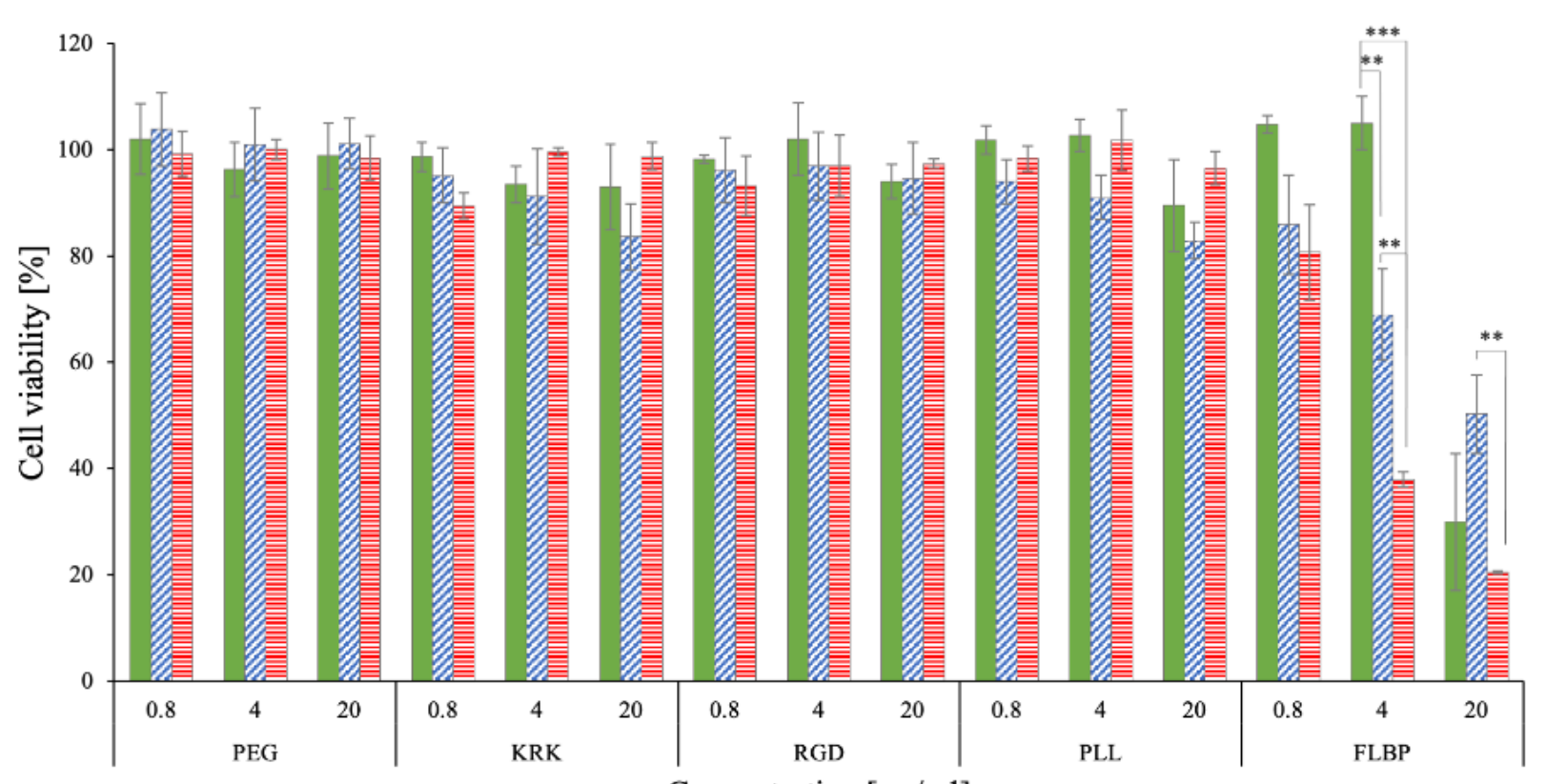

Concentration $[\mu \mathrm{g} / \mathrm{ml}]$

b)

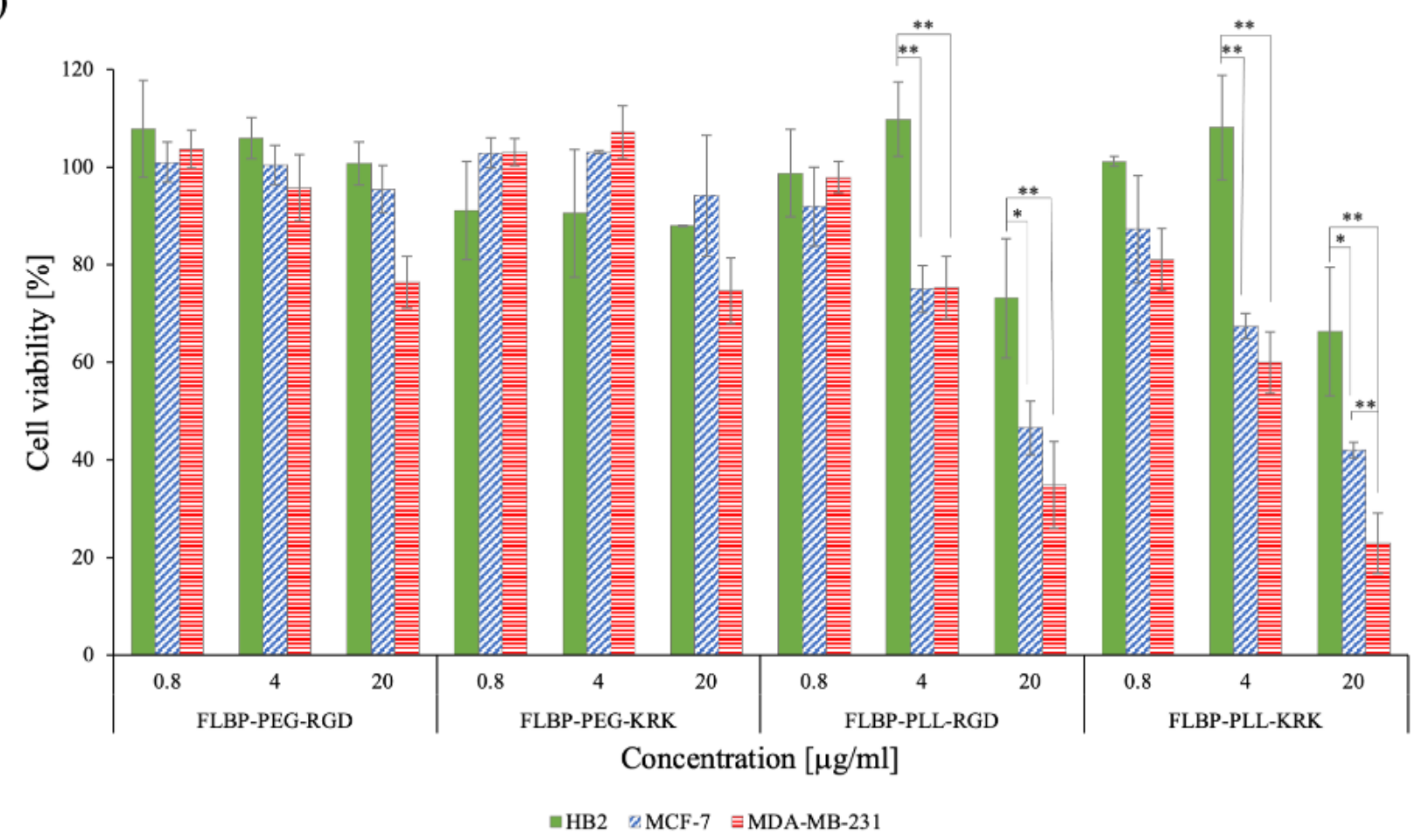

Figure 12

Cell viability [\%] of three different cell lines HB2, MCF-7 and MDA-MB-231 after $72 \mathrm{~h}$ incubation with various concentrations $(0.8,4,20 \mu \mathrm{g}-\mathrm{ml}-1)$ of a) PEG, KRK, RGD, PLL, FLBP and b) FLBP-PEG-RGD, FLBPPEG-KRK, FLBP-PLL-RGD, FLBP-PLL-KRK determined by MTT assay. Data are normalised to control (cells incubated without any additives $[0 \mu \mathrm{g} \mathrm{ml}-1])$ and presented as means $\pm \mathrm{SD}(\mathrm{n}=3$; Student's t-test; *P < $0.05, * * \mathrm{P}<0.01, * * * \mathrm{P}<0.001)$. 